\title{
Aspirin metabolites 2,3-DHBA and 2,5-DHBA inhibit cancer cell growth: Implications in colorectal cancer prevention
}

\author{
RANJINI SANKARANARAYANAN ${ }^{1}$, CHAITANYA K. VALIVETI $^{1}$, RAKESH DACHINENI $^{1}$, \\ D. RAMESH KUMAR ${ }^{2}$, TANA LICK ${ }^{1}$ and G. JAYARAMA BHAT ${ }^{1}$
${ }^{1}$ Department of Pharmaceutical Sciences and Translational Cancer Research Center, College of Pharmacy and Allied Health Professions, Avera Health and Sciences Center, South Dakota State University, Brookings, SD 57007; ${ }^{2}$ Department of Entomology, University of Kentucky, Lexington, KY 40546, USA

Received July 31, 2019; Accepted October 8, 2019

DOI: $10.3892 / \mathrm{mmr} .2019 .10822$

\begin{abstract}
Although compelling evidence exists on the ability of aspirin to treat colorectal cancer (CRC), and numerous theories and targets have been proposed, a consensus has not been reached regarding its mechanism of action. In this regard, a relatively unexplored area is the role played by aspirin metabolites 2,3-dihydroxybenzoic acid (2,3-DHBA) and 2,5-dihydroxybenzoic acid (2,5-DHBA) in its chemopreventive actions. In a previous study, we demonstrated that 2,3-DHBA and 2,5-DHBA inhibited CDK1 enzyme activity in vitro. The aim of the present study was to understand the effect of these metabolites on the enzyme activity of all CDKs involved in cell cycle regulation (CDKs 1, 2, 4 and 6) as well as their effect on clonal formation in three different cancer cell lines. Additionally, in silico studies were performed to determine the potential sites of interactions of 2,3-DHBA and 2,5-DHBA with CDKs. We demonstrated that 2,3-DHBA and 2,5-DHBA inhibits CDK-1 enzyme activity beginning at $500 \mu \mathrm{M}$, while CDK2 and CDK4 activity was inhibited only at higher concentrations $(>750 \mu \mathrm{M})$. 2,3-DHBA inhibited CDK6 enzyme activity from $250 \mu \mathrm{M}$, while 2,5-DHBA inhibited its activity $>750 \mu \mathrm{M}$. Colony formation assays showed that 2,5-DHBA was highly effective in inhibiting clonal formation in HCT-116 and HT-29 CRC cell lines (250-500 $\mu \mathrm{M})$, and in the MDA-MB-231 breast cancer cell line $(\sim 100 \mu \mathrm{M})$. In contrast 2,3-DHBA was effective only in MDA-MB-231 cells $(\sim 500 \mu \mathrm{M})$. Both aspirin
\end{abstract}

Correspondence to: Dr G. Jayarama Bhat, Department of Pharmaceutical Sciences and Translational Cancer Research Center, College of Pharmacy and Allied Health Professions, Avera Health and Sciences Center, South Dakota State University, 1055 Campanile Avenue, Brookings, SD 57007, USA

E-mail: jayarama.gunaje@sdstate.edu

Abbreviations: 2,3-DHBA, 2,3-dihydroxybenzoic acid; 2,5-DHBA, 2,5-dihydroxybenzoic acid

Key words: aspirin and salicylic acid, chemoprevention, colorectal cancer, cyclins, CDKs, CDK inhibitors and salicylic acid failed to inhibit all four CDKs and colony formation. Based on the present results, it is suggested that 2,3-DHBA and 2,5-DHBA may contribute to the chemopreventive properties of aspirin, possibly through the inhibition of CDKs. The present data and the proposed mechanisms should open new areas for future investigations.

\section{Introduction}

Aspirin which was synthesized and patented in 1897 for its analgesic and anti-inflammatory properties has been used now for more than a century, and is one of the most widely used drugs in medicine (1). Its mechanism of action was established in 1971 when Sir John Vane in England demonstrated its ability to decrease the synthesis of prostaglandins responsible for pain, inflammation and fever (2). In 1975, it was discovered that aspirin decreases prostaglandin synthesis by acetylating and inactivating cyclooxygenases (COX) (3). In the years that followed thereafter, aspirin was recommended for the prevention of secondary cardiovascular diseases such as myocardial infarction and stroke, due to its ability to decrease thromboxane A2 in platelets (4). Studies conducted in the past three decades have established yet another therapeutic use for aspirin in the prevention of epithelial cancers, particularly colorectal cancer (CRC), and this was observed even with the low dose aspirin (75 mg) (5-7). Owing to the growing global prevalence of cancer, the chemo-preventive effects of aspirin has gained much attention among physicians, scientists and the public alike. In fact, in 2016 the United States preventive services task force (USPSTF) recommended initiating low dose aspirin use for the prevention of cardiovascular disease and CRC in adults aged 50-59 years' (8). This recommendation was based on increasing evidences on low-dose aspirin's ability to decrease CRC and other cancers $(9,10)$.

Though numerous reports have described potential mechanisms of cancer-prevention by aspirin, its primary mode of action still remains elusive. One of the most discussed mechanism involves the inhibition of COX in platelets (platelet hypothesis) (9-14). Independent of this, other mechanisms have been proposed that includes inhibition of NF-kB (15), induction of polyamine catabolism (16), activation of AMP-kinase $(17,18)$, inhibition of Wnt signaling and 
$\beta$-catenin phosphorylation (19), downregulation of c-myc (20), induction of DNA mismatch repair proteins (21), induction of autophagy (22), and acetylation of p53 and glucose-6-phosphate dehydrogenase $(23,24)$ to name a few. Many of these effects were detected mainly at high concentrations of aspirin (often at millimolar concentrations) which are not reached in vivo in the systemic circulation (maximum reported concentration is $142 \mu \mathrm{M}$ with $1.2 \mathrm{~g}$ tablets/4-6h) (16). The inability to accurately pinpoint the mechanism involved also stems from the failure to differentiate the primary proximal effects from its associated downstream signaling events and the subsequently observed biological responses (25). Additionally, studies show that aspirin is more effective in decreasing the incidence of CRC as compared to other cancers such as breast, prostate, lung and skin (26-28); however, it is still not clear why aspirin is more effective against CRC as compared to other cancers.

Our laboratory has been focusing on determining a role for aspirin and salicylic acid metabolites 2,3-dihydroxybenzoic acid (2,3-DHBA) and 2,5-dihydroxybenzoic acid (2,5-DHBA), known to be generated in the body by the cytochrome P-450 (CYP450) catalyzed reactions (29), in the prevention of CRC. Interestingly, similar dihydroxybenzoic acids have also been reported to be generated from aspirin by the gut microflora (30). In a previous study we demonstrated the ability of 2,3-DHBA and 2,5-DHBA to inhibit cyclin dependent kinase 1 (CDK1) activity in vitro (31). However, an extended study on the effect of these metabolites on other CDKs involved in cell-cycle regulation (CDK2, CDK4 and CDK6) as well as the demonstration of their ability to inhibit cancer cell growth were not reported. As a dysregulated cell cycle is one of the hallmarks of cancer, it was important to determine if 2,3-DHBA and 2,5-DHBA affected cancer cell growth by inhibiting these CDKs to gain a comprehensive understanding of their mechanism of action. In the present study, we investigated the effect of 2,3-DHBA and 2,5-DHBA on CDKs 1, 2, 4 and 6 enzyme activities and determined their potential sites of interaction within these enzymes. In addition, we also performed studies to determine the effect of these metabolites on cancer cell proliferation. Our results show that although aspirin and salicylic acid showed potential interactions with the CDK enzymes, only their metabolites were effective in inhibiting CDK enzyme activity and cancer cell proliferation. More specifically, these metabolites inhibited CDK1 and CDK6 enzyme activity. Our results show that among the two aspirin metabolites, 2,5-DHBA is highly effective in inhibiting cell proliferation in three different cell lines (HCT-116, HT-29 and MDA-MB-231) whereas 2,3-DHBA was capable of inhibiting cell growth only in MDA-MB-231 cells. Our findings suggests a role for these metabolites in aspirin's chemo-preventive actions.

\section{Materials and methods}

Cell lines, recombinant proteins and reagents. HCT-116 (colorectal carcinoma), HT-29 (colorectal adenocarcinoma) and MDA-MB-231 (breast adenocarcinoma) cell lines were purchased from American Type Culture Collection (ATCC). MDA-MB-231 cells were grown in RPMI media while HCT-116 and HT-29 cells were cultured in McCoy's 5A media, both supplemented with $10 \%$ FBS and antibiotics for $24 \mathrm{~h}$ before treatment with specified compounds for indicated times. Authentication of cell lines was done by ATCC through their DNA-STR profile. CDK1/Cyclin B1, CDK2/Cyclin A2, CDK4/Cyclin D1, Retinoblastoma (C-term) and kinase buffer were purchased from SignalChem. Aspirin, salicylic acid and trypsin-EDTA solution were purchased from Sigma-Aldrich; H1 Histones were obtained from EMD Millipore; $\left[{ }^{32} \mathrm{P}\right] \gamma$-ATP from PerkinElmer; 2,3-DHBA, 2,5-DHBA and all other reagents mentioned in this study were obtained from Thermo Fischer Scientific, Inc.

In vitro $C D K$ assay. In vitro $\mathrm{CDK}$ assays, to measure enzyme activity, were performed as described by the manufacturer (32-35) and previously published protocols $(31,36,37)$. Briefly, purified enzyme was aliquoted into the reaction buffer and incubated with indicated compounds (aspirin, salicylic acid, 2,3-DHBA and 2,5-DHBA) at various concentrations for $10 \mathrm{~min}$. at room temperature. The reaction mixture was incubated with kinase buffer containing $15 \mu \mathrm{M}$ ATP, $2 \mu \mathrm{Ci}$ of $\left[{ }^{32} \mathrm{P}\right] \gamma$-ATP, $5 \mu \mathrm{g}$ of $\mathrm{H} 1$ Histone $(7.5 \mu \mathrm{g} /$ reaction added as substrate for CDKs 1 and 2$)$ or retinoblastoma $(1.5 \mu \mathrm{g} /$ reaction added as substrate for CDKs 4 and 6 ), at $30^{\circ} \mathrm{C}$ for $20 \mathrm{~min}$ in a final volume of $50 \mu \mathrm{l}$. The reactions were halted by adding EDTA to a final concentration of $20 \mathrm{mM}$ and addition of $4 \mathrm{X}$ loading buffer. The samples were boiled for $10 \mathrm{~min}$, analyzed by 8 or $10 \%$ SDS-PAGE, stained using coomassie brilliant blue (R250) to confirm equal loading of the H1 histones and Retinoblastoma protein. The molecular weight of the proteins were confirmed by molecular weight markers. The gel was dried, and exposed to X-ray film. NIH ImageJ software was used to quantify the intensities of the bands. The normalization of the band intensities of the phosphorylated H1 histones/ Retinoblastoma proteins were determined by comparing to the control, which is the phosphorylation in the absence of these compounds.

Molecular docking studies. The crystallographic three dimensional structures of CDK1 (4Y72 A chain), CDK2 (1FIN A chain), CDK4 (3G33 A chain) and CDK6 (4AUA) were retrieved from the Protein Data Bank (PDB). Energy minimization for these proteins was performed using Gromacs 3.3.1 package utilizing GROMOS96 force field (38). The energy-minimized molecules were used as the receptors for virtual small molecule docking with aspirin, salicylic acid, 2,3-DHBA, 2,5-DHBA using AutoDock Vina. The results were visualized by PYMOL molecular graphics system version 1.3.

Cell proliferation. Approximately 250,000 cells were seeded per $100 \mathrm{~mm}$ plates containing 10\% FBS and grown overnight. Cells were left untreated (control) or were treated with drugs at various concentrations and incubated for $48 \mathrm{~h}$. The floating cells in the spent media (if any) were collected, pooled with the trypsinized cells, and counted using the Nexcelom Cellometer Auto T4 cell counter.

Clonogenic assay. Clonogenic assays were performed as previously described (36). Cells were seeded at a density of 500 cells $/ 100 \mathrm{~mm}$ plate and grown for $48 \mathrm{~h}$ following which cells were left untreated (control) or treated with compounds (aspirin, salicylic acid, 2,3-DHBA and 2,5-DHBA) at the concentrations indicated. The spent media was replaced 


\section{CDK1}

A
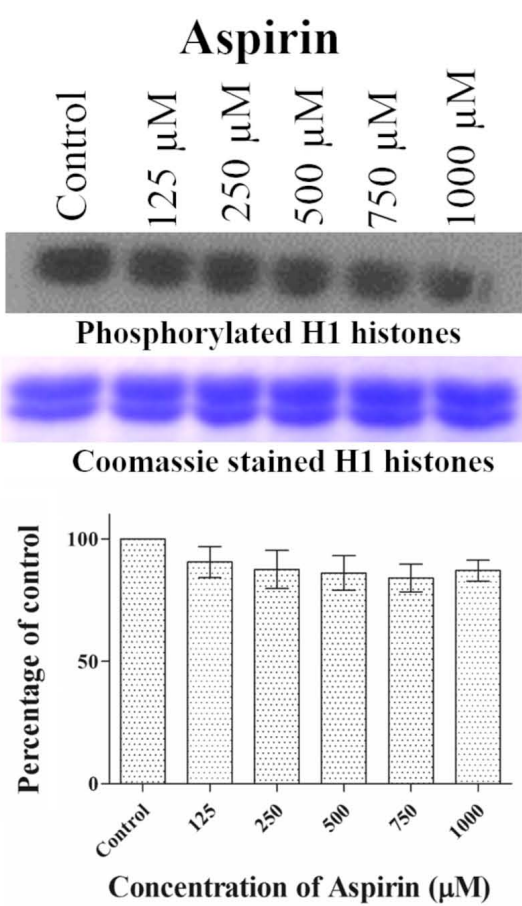

C

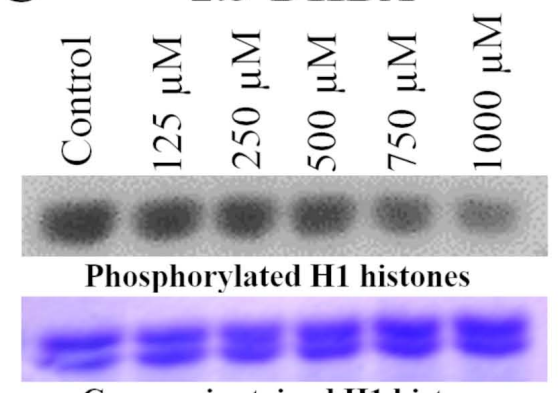

Coomassie stained H1 histones

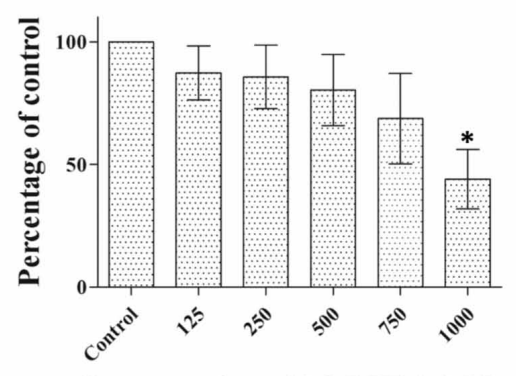

Concentration of 2.3-DHBA $(\mu \mathrm{M})$
B Salicylic acid

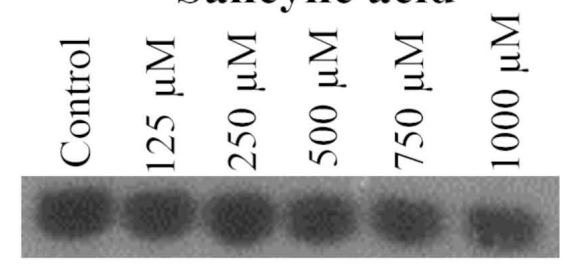

Phosphorylated H1 histones
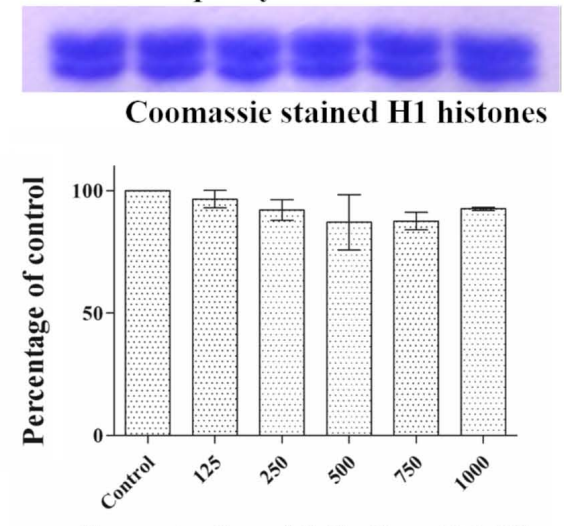

Concentration of Salicylic acid $(\mu \mathrm{M})$

D

2.5-DHBA

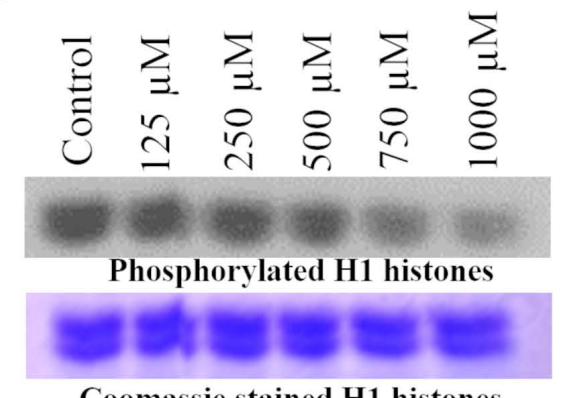

Coomassie stained H1 histones

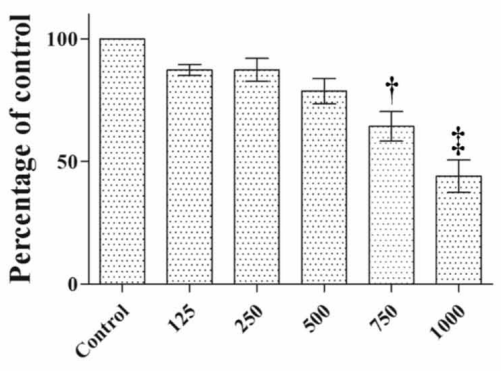

Concentration of 2.5-DHBA $(\mu \mathrm{M})$

P-value $,<0.05^{*},<0.01 \dagger,<0.001 \dagger$.

Figure 1. Effect of different concentrations of (A) aspirin, (B) salicylic acid, (C) 2,3-DHBA and (D) 2,5-DHBA on CDK1 enzyme activity. H1 histones were used as the substrate for CDK1. Upper panel shows phosphorylation of H1 Histones in the presence of different concentrations of each compound. The middle panel shows the coomassie blue stained proteins. Lower panel represents the quantification of the bands in upper panel. ${ }^{*} \mathrm{P}<0.05,{ }^{* * *} \mathrm{P}<0.01,{ }^{* * *} \mathrm{P}<0.001 \mathrm{vs}$. Control. 2,3-DHBA, 2,3-dihydroxybenzoic acid; 2,5-DHBA, 2,5-dihydroxybenzoic acid.

with fresh media containing the respective compounds every 5-6 days. Cells were incubated for 21 days, fixed with $100 \%$ methanol for $20 \mathrm{~min}$, and stained with $0.5 \%$ crystal violet prepared in $25 \%$ methanol. The colonies were then photographed and quantified using NIH ImageJ software.
Statistical analysis. All experiments were repeated 3-6 times independently of each other. One-way ANOVA followed by Tukey's post-hoc tests were adopted to compare group differences with the control. $\mathrm{P}<0.05$ was considered to indicate a statistically significant difference. 


\section{CDK2}

A

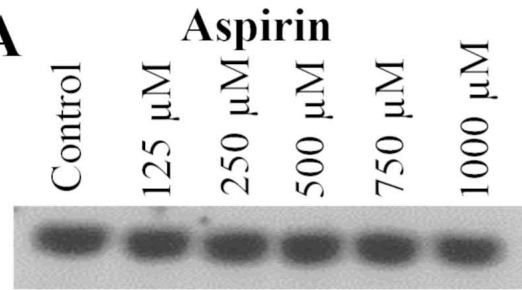

Phosphorylated H1 histones

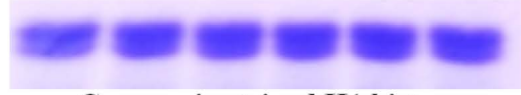

Coomassie stained H1 histones

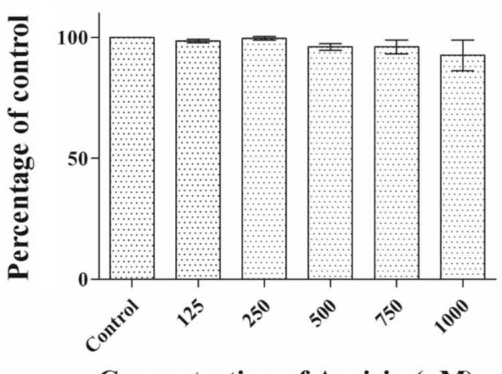

Concentration of Aspirin $(\mu \mathrm{M})$
B
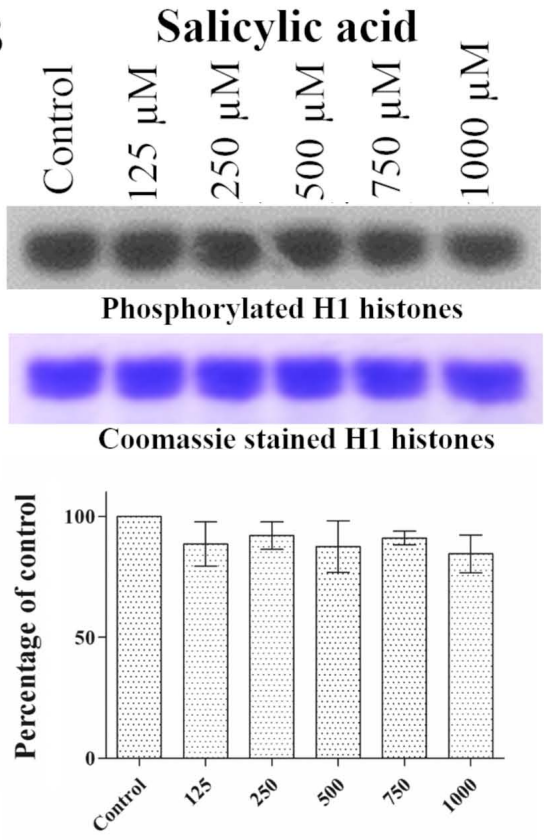

Concentration of Salicylic acid $(\mu \mathrm{M})$

C

2.3-DHBA
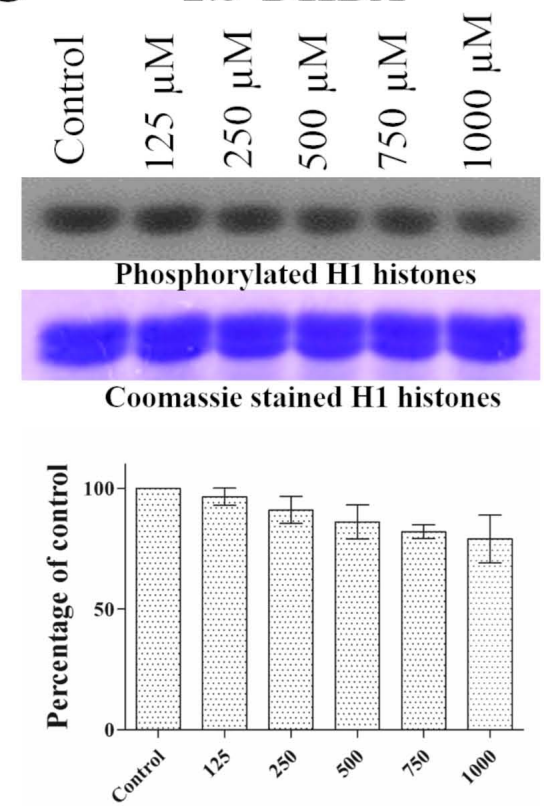

Concentration of 2.3-DHBA $(\mu \mathrm{M})$
D
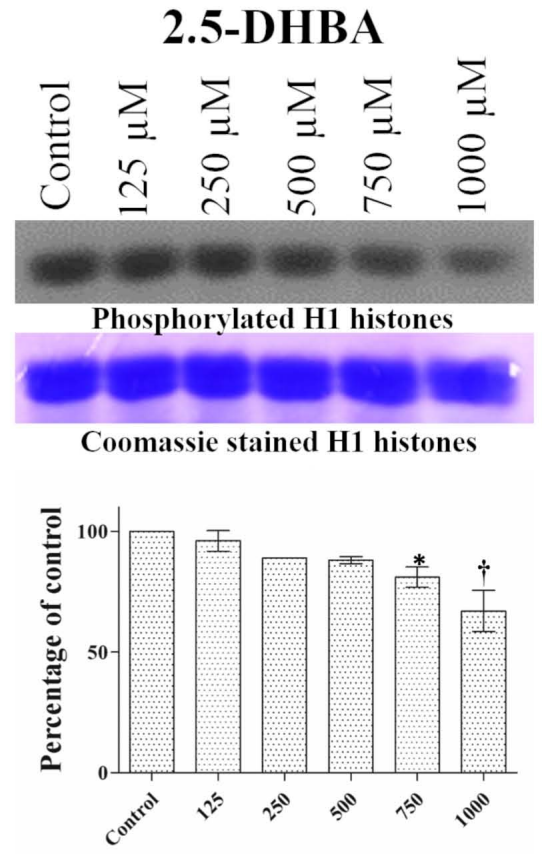

Concentration of 2.5-DHBA $(\mu \mathrm{M})$

P-value, $<0.05^{*},<0.01 \dagger,<0.001 \ddagger$.

Figure 2. Effect of different concentrations of (A) aspirin, (B) salicylic acid, (C) 2,3-DHBA and (D) 2,5-DHBA on CDK2 enzyme activity. H1 histones were used as the substrate for CDK2. Upper panel shows phosphorylation of H1 Histones in the presence of different concentrations of each compound. The middle panel shows the coomassie blue stained proteins. Lower panel represents the quantification of the bands in upper panel. " $\mathrm{P}<0.05$, "* $\mathrm{P}<0.01 \mathrm{vs}$. Control.2,3-DHBA, 2,3-dihydroxybenzoic acid; 2,5-DHBA, 2,5-dihydroxybenzoic acid.

\section{Results}

Effect of aspirin, salicylic acid, 2,3-DHBA and 2,5-DHBA on CDK enzyme activity. We initiated this study by determining the dose-dependent effect of aspirin, salicylic acid, 2,3-DHBA and 2,5-DHBA on recombinant CDKs 1, 2, 4 and 6 by measuring the phosphorylation pattern through in vitro kinase assays. Fig. 1 shows that CDK1 activity remained unaffected following treatment with aspirin and salicylic acid at all concentrations tested (125 $\mu \mathrm{M}$ to $1 \mathrm{mM})$; however, 2,3-DHBA and 2,5-DHBA inhibited CDK1 activity, confirming our previously published results (31). In both cases, inhibition was around $20 \%$ at $500 \mu \mathrm{M}, 40 \%$ at $750 \mu \mathrm{M}$ and $60 \%$ at $1,000 \mu \mathrm{M}$. $\mathrm{CDK} 2$ activity remained unchanged upon exposure to 


\section{CDK4}

A

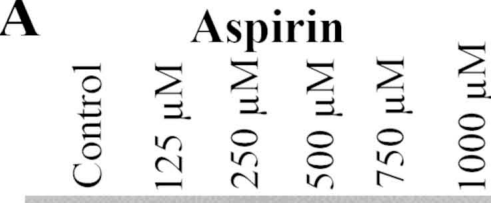

Phosphorylated Retinoblastoma protein

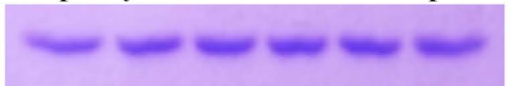

Coomassie stained Retinoblastoma protein

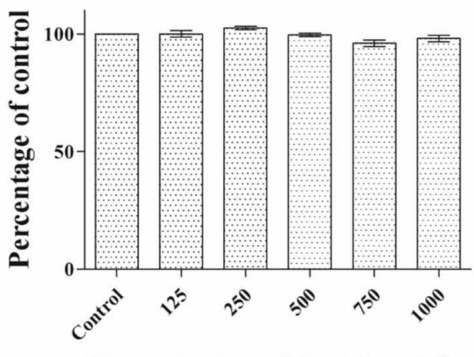

Concentration of Aspirin $(\mu \mathrm{M})$

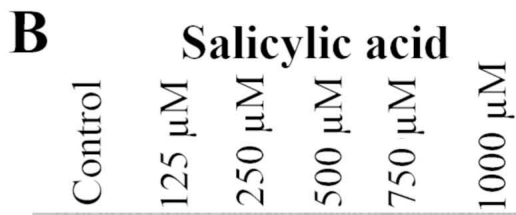

Phosphorylated Retinoblastoma protein

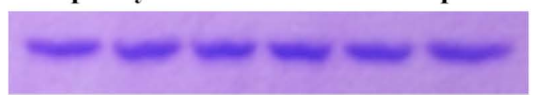

Coomassie stained Retinoblastoma protein

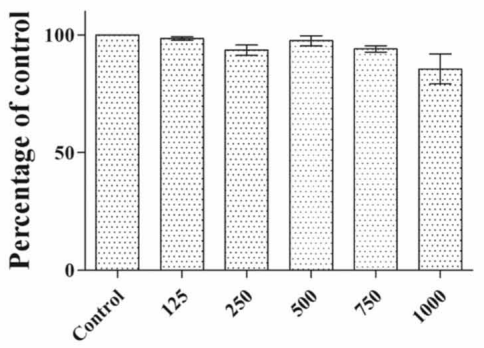

Concentration of Salicylic acid $(\mu \mathrm{M})$
C

\section{3-DHBA}

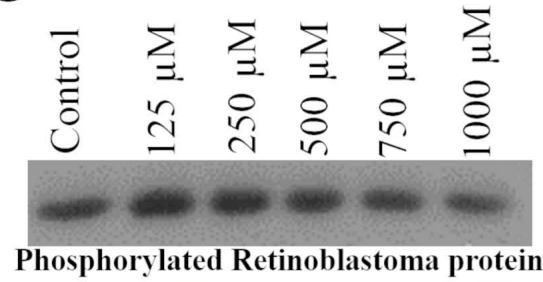

Phosphorylated Retinoblastoma protein

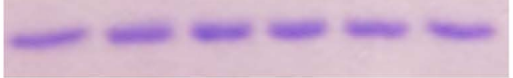

Coomassie stained Retinoblastoma protein

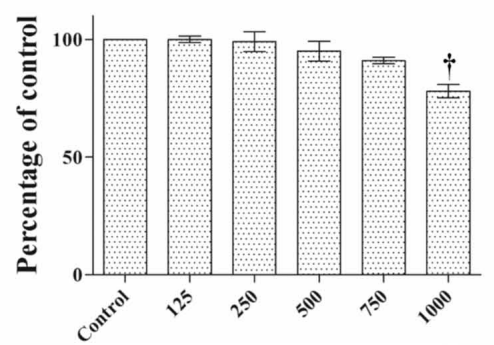

Concentration of 2.3-DHBA $(\mu \mathrm{M})$
D

2.5-DHBA

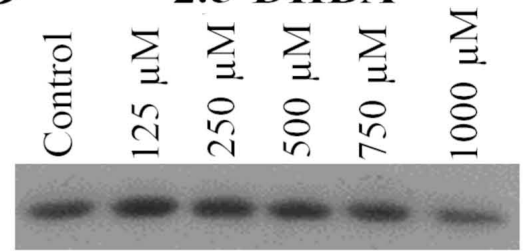

Phosphorylated Retinoblastoma protein

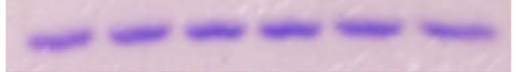

Coomassie stained Retinoblastoma protein

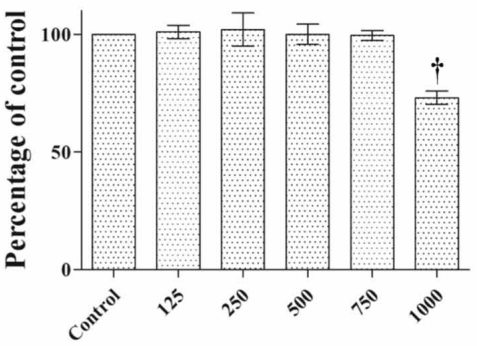

Concentration of 2.5-DHBA $(\mu \mathrm{M})$

P-value, $<0.05^{*},<0.01 \dagger,<0.001 \dagger$.

Figure 3. Effect of different concentrations of (A) aspirin, (B) salicylic acid, (C) 2,3-DHBA and (D) 2,5-DHBA on CDK4 enzyme activity. Retinoblastoma protein was used as the substrate for CDK4. Upper panel shows phosphorylation of retinoblastoma protein in the presence of different concentrations of each compound. The middle panel shows the coomassie blue stained proteins. Lower panel represents the quantification of the bands in upper panel. ${ }^{* *} \mathrm{P}<0.01 \mathrm{vs}$. Control.2,3-DHBA, 2,3-dihydroxybenzoic acid; 2,5-DHBA, 2,5-dihydroxybenzoic acid.

aspirin and salicylic acid while inhibition was observed with 2,3-DHBA and 2,5-DHBA, especially at higher concentrations (>750 $\mu \mathrm{M}$; Fig. 2). Similar to CDK1 and CDK2, aspirin and salicylic acid both failed to inhibit CDK4 and CDK6 enzyme activity (Figs. 3 and 4). 2,3-DHBA and 2,5-DHBA inhibited CDK4 activity at $1,000 \mu \mathrm{M}$. 2,3-DHBA was able to inhibit CDK6 enzyme activity beginning at $250 \mu \mathrm{M}$, while 2,5-DHBA inhibited CDK6 enzyme activity at concentrations $>750 \mu \mathrm{M}$. These results show 2,3-DHBA and 2,5-DHBA were able to inhibit CDKs 1, 2, 4, and 6 activities to different degrees. It is also important to note that the inhibition observed with CDK1 by 2,3-DHBA and 2,5-DHBA, and CDK-6 by 2,3-DHBA was significantly greater compared to inhibition of other CDKs by these compounds. 


\section{CDK6}

A

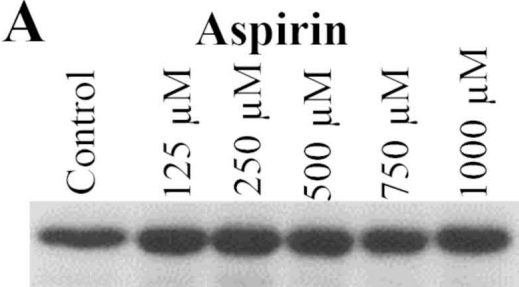

Phosphorylated Retinoblastoma protein

Coomassie stained Retinoblastoma protein

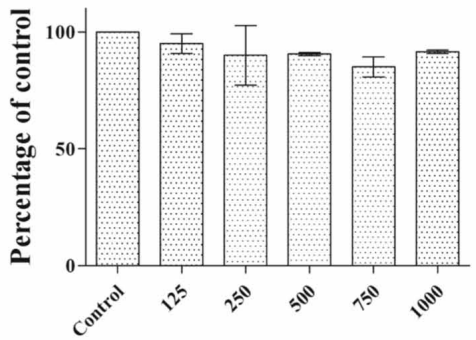

Concentration of Aspirin $(\mu \mathrm{M})$

C

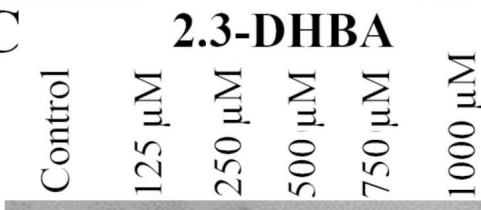

Phosphorylated Retinoblastoma protein

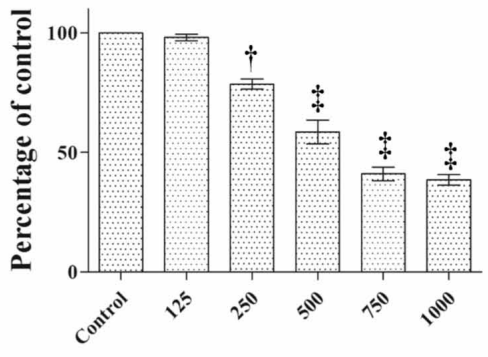

Concentration of 2.3-DHBA $(\mu \mathrm{M})$
B

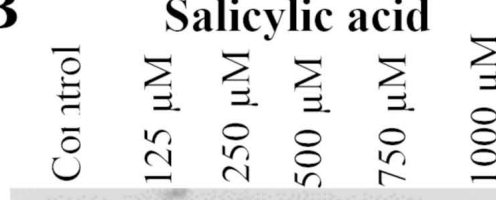

Phosphorylated Retinoblastoma protein

Coomassie stained Retinoblastoma protein

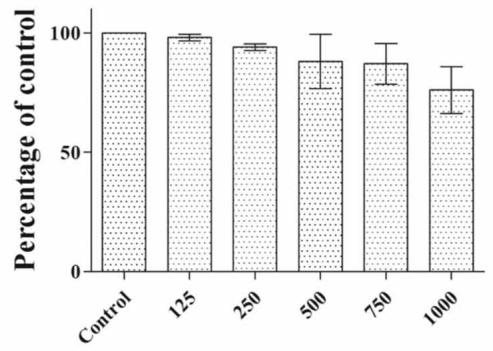

Concentration of Salicylic acid $(\mu \mathrm{M})$
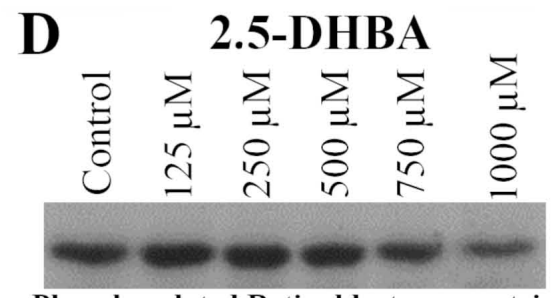

Phosphorylated Retinoblastoma protein

Coomassie stained Retinoblastoma protein

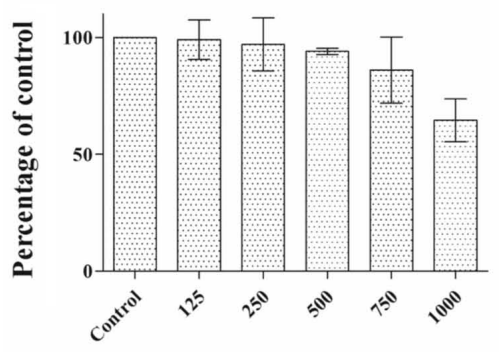

Concentration of 2.5-DHBA $(\mu \mathrm{M})$

P-value, $<0.05^{*},<0.01 \dagger,<0.001 \uparrow$.

Figure 4. Effect of different concentrations of (A) aspirin, (B) salicylic acid, (C) 2,3-DHBA and (D) 2,5-DHBA on CDK6 enzyme activity. Retinoblastoma protein was used as the substrate for CDK6. Upper panel shows phosphorylation of retinoblastoma protein in the presence of different concentrations of each compound. The middle panel shows the coomassie blue stained proteins. Lower panel represents the quantification of the bands in upper panel. ${ }^{* *} \mathrm{P}<0.01$, ${ }_{* * * *}^{*}<0.001$ vs. Control. 2,3-DHBA, 2,3-dihydroxybenzoic acid; 2,5-DHBA, 2,5-dihydroxybenzoic acid.

Docking studies reveal binding pockets for aspirin, salicylic, 2,3-DHBA, and 2,5-DHBA. AutoDock Vina was used to predict the potential interactions of aspirin, salicylic acid, 2,3-DHBA and 2,5-DHBA with CDKs 1, 2, 4 and 6. The binding free energy and hydrogen bond lengths were also determined. The results of the docking studies are shown in Table I and Fig. 5 (line model). All the compounds tested interacted with CDKs and utilized amino acids either residing in the active site or at alternate binding pockets. Docking studies revealed that 2,3-DHBA potentially interacts with CDK1 through Asp146; with CDK2 it utilizes Lys33, and Asp145; with CDK4, it interacts through Cys68 and His158 and with CDK6 it binds to Asp134, Tyr292, Ala291 and Thr198. 2,5-DHBA interacts with CDK1 using Asp146; with CDK2 it utilizes Asp145 and Lys33; with CDK4 through His158; and with CDK6 it uses Lys43, Tyr24 and Gly25. Salicylic acid and aspirin also interacted with all 4 CDKs (Table I), although CDK inhibition was not observed in vitro (Figs. 1-4). Notable interactions are that between the drug molecules and Asp146 of CDK1, as this amino acid is involved in CDK-ATP interactions (39). 
Table I. Free energy binding values and hydrogen bond lengths for the interaction of aspirin, salicylic acid, 2,3-DHBA and 2,5-DHBA with CDK1, CDK2, CDK4 and CDK6.

\section{$\mathrm{A}, \mathrm{CDK} 1$}

\begin{tabular}{lllll}
\hline Ligand & \multicolumn{1}{c}{ Interacting amino acids } & Measurement, $\mathrm{A}^{\circ}$ & No of $\mathrm{H}$ bonds & Energy value, $\mathrm{kCal} / \mathrm{mol}$ \\
\hline Aspirin & Asn133, Tyr15 & $2.5,3.0$ & 2 & -6.6 \\
Salicylic acid & Asp146, Lys33 & $2.8,3.5$ & 2 & -6.4 \\
2,3-DHBA & Asp146 & 2.9 & 1 & -5.9 \\
2,5-DHBA & Asp146 & 2.9 & 1 & -5.9 \\
\hline
\end{tabular}

\section{$\mathrm{B}, \mathrm{CDK} 2$}

\begin{tabular}{llllr}
\hline Ligand & \multicolumn{1}{c}{ Interacting amino acids } & Measurement, $\mathrm{A}^{\circ}$ & No of H bonds & Energy value, $\mathrm{kCal} / \mathrm{mol}$ \\
\hline Aspirin & Asp145, Glu51, Lys33(2) & $3.2,2.6,3.1,3.0$ & 4 & -6.2 \\
Salicylic acid & Asp145, Lys33(2) & $3.3,3.0,3.3$ & 3 & -5.7 \\
2,3-DHBA & Lys33, Asp145 & $3.2,3.2$ & 2 & -5.6 \\
2,5-DHBA & Asp145, Lys33(2) & $3.2,2.9,2.9$ & 3 & -5.9 \\
\hline
\end{tabular}

\section{C, CDK4}

\begin{tabular}{lllll}
\hline Ligand & \multicolumn{1}{c}{ Interacting amino acids } & Measurement, $\mathrm{A}^{\circ}$ & No of H bonds & Energy value, $\mathrm{kCal} / \mathrm{mol}$ \\
\hline Aspirin & His 158, Gln183 & $2.9,2.0$ & 2 & -5.8 \\
Salicylic acid & His 158, Gln183 & $2.8,1.8$ & 2 & -5.4 \\
2,3-DHBA & His 158, Cys68 & $3.1,2.2$ & 2 & -5.8 \\
2,5-DHBA & His158 & 3.1 & 1 & -5.4 \\
\hline
\end{tabular}

\section{D, CDK6}

\begin{tabular}{llllr}
\hline Ligand & \multicolumn{1}{c}{ Interacting amino acids } & Measurement, $\mathrm{A}^{\circ}$ & No of $\mathrm{H}$ bonds & Energy value, $\mathrm{kCal} / \mathrm{mol}$ \\
\hline Aspirin & Lys43 & 2.9 & 1 & -5.4 \\
Salicylic acid & Gly165, Leu166, Arg144 & $3.1,2.8,3.0$ & 3 & -5.1 \\
2,3-DHBA & Asp134, Tyr292, Ala291(2), Thr198 & $2.0,3.0,3.2,2.9,2.9$ & 5 & -5.4 \\
2,5-DHBA & Lys43(2), Tyr24, Gly25 & $3.2,3.2,3.2,3.2$ & 4 & -5.3 \\
\hline
\end{tabular}

2,3-DHBA, 2,3-dihydroxybenzoic acid; 2,5-DHBA, 2,5-dihydroxybenzoic acid.

Although salicylic acid interacted with CDK1 through Asp146 and Lys33 and CDK2 through Asp145 and Lys33, it is not clear at this stage why it failed to cause inhibition of the enzyme activity. This may be due to the formation of an intramolecular hydrogen bond between its carboxyl and hydroxyl groups which may hinder its interactions with CDKs.

Effect of aspirin, salicylic acid, 2,3-DHBA and 2,5-DHBA on colony formation. Clonogenic assay was performed to determine the effectiveness of aspirin, salicylic acid, 2,3-DHBA and 2,5-DHBA on colony formation in HCT-116 and HT-29 colon cancer cells as well as MDA-MB-231 breast cancer cells. HCT-116 and HT-29 cells were chosen to study the effect of these compounds as these cell line have been extensively used in studies pertaining to aspirin's biological effects $(40,41)$;
MDA-MB-231 cells were chosen to determine if this effect was mimicked in another cancer cell line. We observed that aspirin and salicylic acid both failed to inhibit colony formation in HCT-116 (Fig. 6A and B), HT-29 (Fig. 7A and B) and MDA-MB-231 cells (Fig. 8A and B). 2,3-DHBA was effective in MDA-MB-231 cells at higher concentrations $(>500 \mu \mathrm{M})$ (Fig. 8C), while it was ineffective in HCT-116 (Fig. 6C) and HT-29 cells (Fig. 7C). Interestingly, 2,5-DHBA exhibited a dose dependent effect on colony formation in all cell lines examined (Figs. 6D, 7D, 8D). In HCT-116 cells, decreased colony formation was observed with 2,5-DHBA at concentrations $>250 \mu \mathrm{M}$, in HT-29 cells at concentrations $>200 \mu \mathrm{M}$, and in MDA-MB-231 cells, beginning at $50 \mu \mathrm{M}$. In contrast, two other salicylic acid derivatives 2,4-DHBA and 2,6-DHBA were unable to inhibit colony formation in 

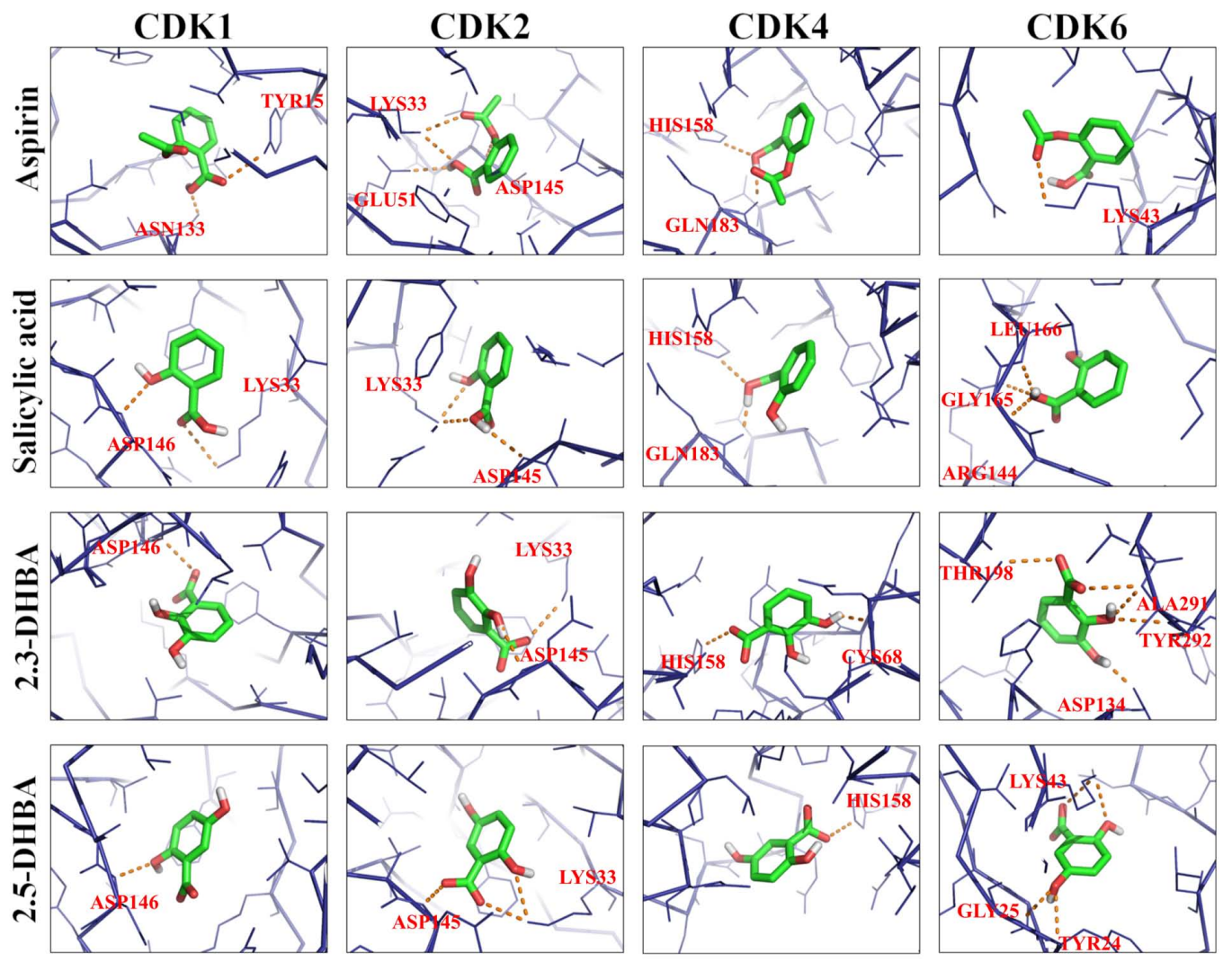

Figure 5. Line model showing the interactions of aspirin, salicylic acid, 2,3-DHBA and 2,5-DHBA with CDK1, CDK2, CDK4 and CDK6.

MDA-MB-231 cells (Fig. S1). These results clearly show that although the sensitivity varies among different cell lines, both 2,3-DHBA and 2,5-DHBA exhibit the ability to inhibit cancer cell proliferation in contrast to aspirin and salicylic acid.

Interestingly, 2,3-DHBA and 2,5-DHBA were ineffective in inhibiting cell proliferation in MDA-MB-231 cells over a range of concentrations (125-1,000 $\mu \mathrm{M})$ for 24-48 h (Fig. S2). We suggest that the lack of inhibition in acute treatment observed may be related to the poor uptake of these compounds.

\section{Discussion}

Despite the growing evidence for aspirin's ability to decrease CRC, the mechanisms involved remain poorly defined. Numerous hypotheses commencing from the COX inhibition in platelets $(9,11,12)$ to increased expression of DNA repair proteins, transcription factors and interconnected signaling pathways have been proposed (42-45); however, a consensus has not been reached regarding the target/pathway(s) primarily responsible for its anti-cancer effects (46). In this research paper, we tested the hypothesis that aspirin metabolites 2,3-DHBA and 2,5-DHBA may mediate its chemopreventive actions by inhibiting CDKs and affecting cell growth. We provide evidence that 2,3-DHBA and 2,5-DHBA inhibit CDKs involved in cell-cycle regulation (CDKs 1,2,4 and 6), although to different degrees. Inhibition of CDK1 by 2,3-DHBA and 2,5-DHBA was observed at $500 \mu \mathrm{M}$, and CDK-6 by 2,3-DHBA was observed starting at $250 \mu \mathrm{M}$, however, inhibition of other CDKs by these compounds required much higher concentrations $(750 \mu \mathrm{M})$, suggesting that CDK1 and CDK6 are better targets for 2,3-DHBA and/or 2,5-DHBA. In contrast, aspirin and salicylic acid both failed to inhibit CDK-1, 2, 4 and 6 enzyme activity. Through molecular docking studies we identified potential sites of these interactions; most of the interacting amino acids appear to be localized in the active site of these enzymes. Importantly, we also demonstrated the ability of aspirin/salicylic acid metabolites to inhibit clonal formation in cancer cell lines. 2,5-DHBA inhibited colony formation in a dose-dependent manner in three different cancer cell lines (HCT-116, HT-29 and MDA-MB-231). In contrast, 2,3-DHBA exhibited effective inhibition in MDA-MB-231 cells alone. These results suggest that 2,3-DHBA and 2,5-DHBA may be involved in aspirin's chemopreventive actions. Our findings raise two important questions: 1) What are the sources of the aspirin metabolites 2,3-DHBA and 2,5-DHBA?; 2) Are there unique scenarios that gives an anatomical advantage to 2,3-DHBA and 2,5-DHBA to act against CRC?

Plain aspirin (non-enteric coated) is absorbed in the stomach where the acidic environment protects it from deacetylation and ionization, resulting in its faster absorption; however, aspirin may also be absorbed in the upper small intestine and enter into the hepatic portal vein (47-49). In addition, lymphatic uptake of some aspirin and salicylic acid has been reported (49). We hypothesize that aspirin's preferential effect against CRC (over other tissues) may be related to the generation of salicylic acid that occurs both through hydrolysis and the action of gut esterases (50) in the intestine or colon. Intact aspirin's bioavailability is between $50-68 \%(51,52)$, and it is estimated that nearly $29-39 \%$ of aspirin may be hydrolyzed in the GI tract, particularly in the duodenum and ileum (52). 

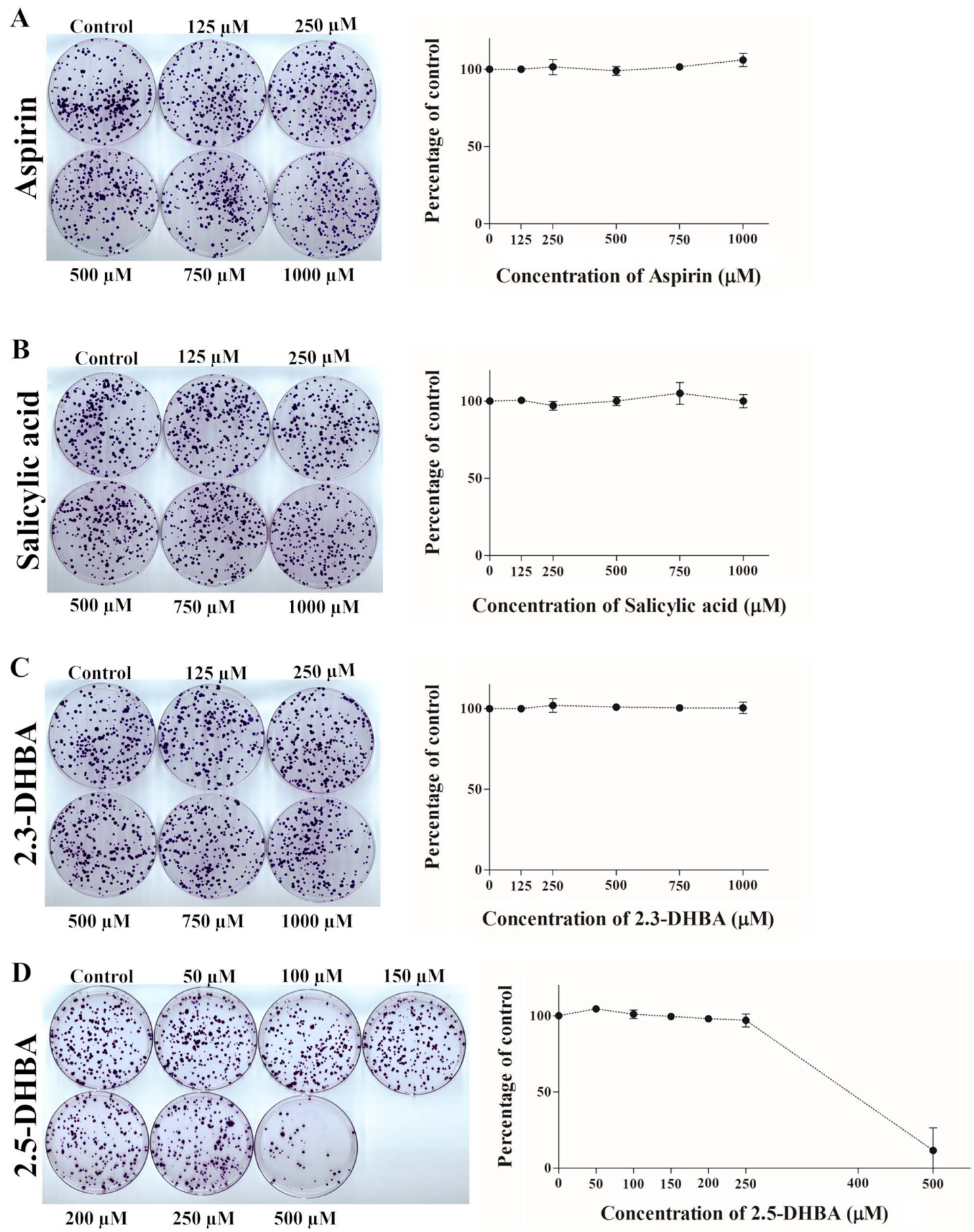

Figure 6. Effect of (A) aspirin, (B) salicylic acid, (C) 2,3-DHBA and (D) 2,5-DHBA on colony formation in HCT-116 cells. Quantification of the data is shown beside the crystal violet stained image of the colonies. The graph is represented as the mean \pm standard deviation. 2,3-DHBA, 2,3-dihydroxybenzoic acid; 2,5-DHBA, 2,5-dihydroxybenzoic acid.

Therefore, it can be argued that epithelial cells of the intestine and colon are likely to be exposed to substantially higher concentrations of salicylic acid compared to other tissues in the body. With enteric coated aspirin, the concentration of aspirin/salicylic acid exposed to the GI cells may be even greater than non-enteric coated tablets as the bioavailability of intact aspirin from enteric coated tablets is significantly lower compared to plain aspirin due to slow release and absorption in the intestine $(47,53)$.

Aspirin in the systemic circulation is known to be metabolized in the liver to 2,3-DHBA and 2,5-DHBA through the action of cytochrome P450 (CYP450s) enzymes. However, it is unlikely that these liver generated metabolites contribute to the anti-cancer effect in colorectal tissues due to their low concentrations in the plasma (29). We suggest that there are two routes through which intestinal epithelial cells may get exposed to 2,3-DHBA and 2,5-DHBA. As intestinal epithelial cells also express CYP450s similar to the isoforms expressed in the liver involved in aspirin metabolism (54), one would expect aspirin metabolites to be generated in these cells; however, it is not clear at this stage to what extent these metabolites are produced within the GI cells. Since exposure of HCT-116, 

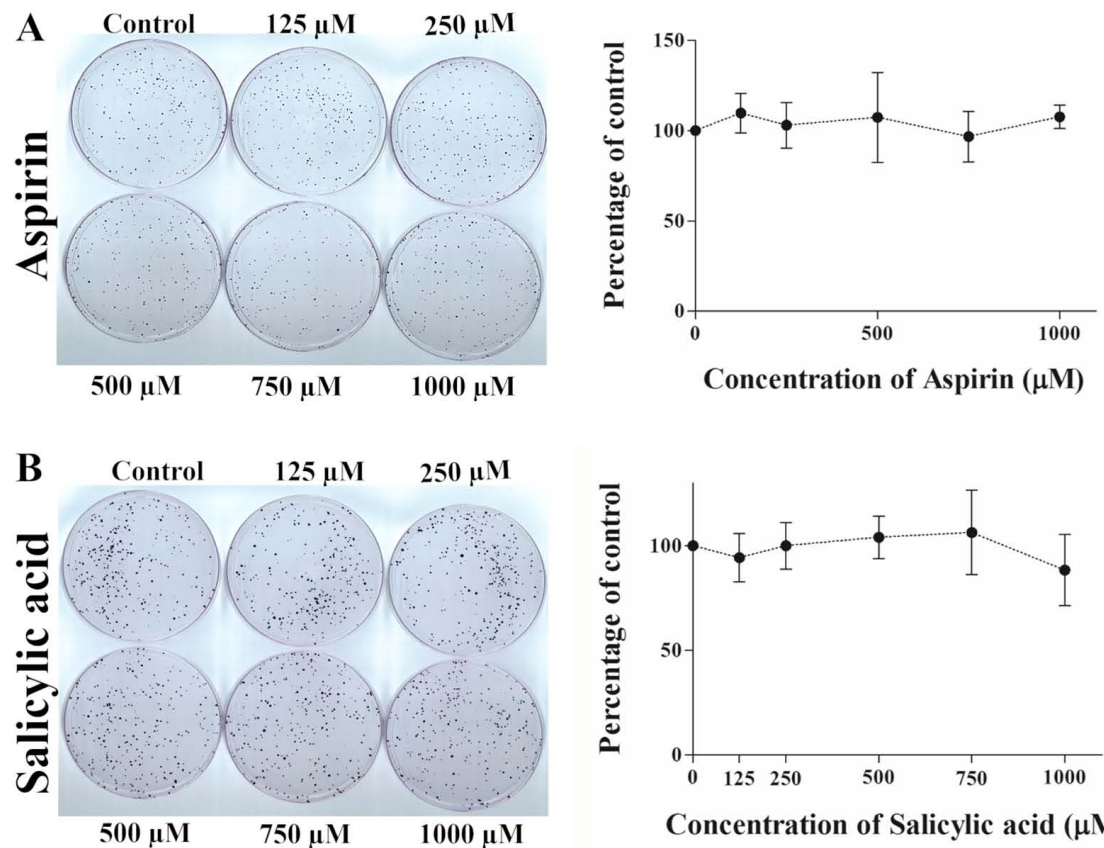

Concentration of Salicylic acid $(\mu \mathrm{M})$
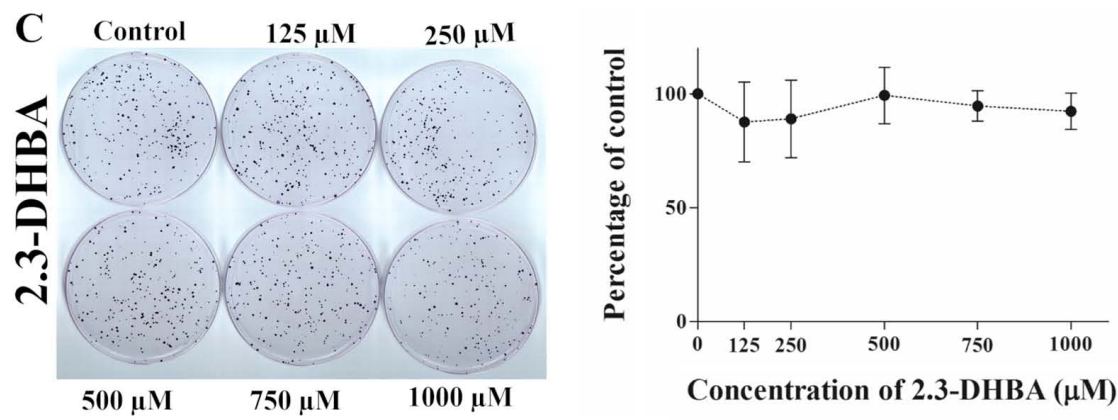

Concentration of 2.3-DHBA $(\mu \mathrm{M})$
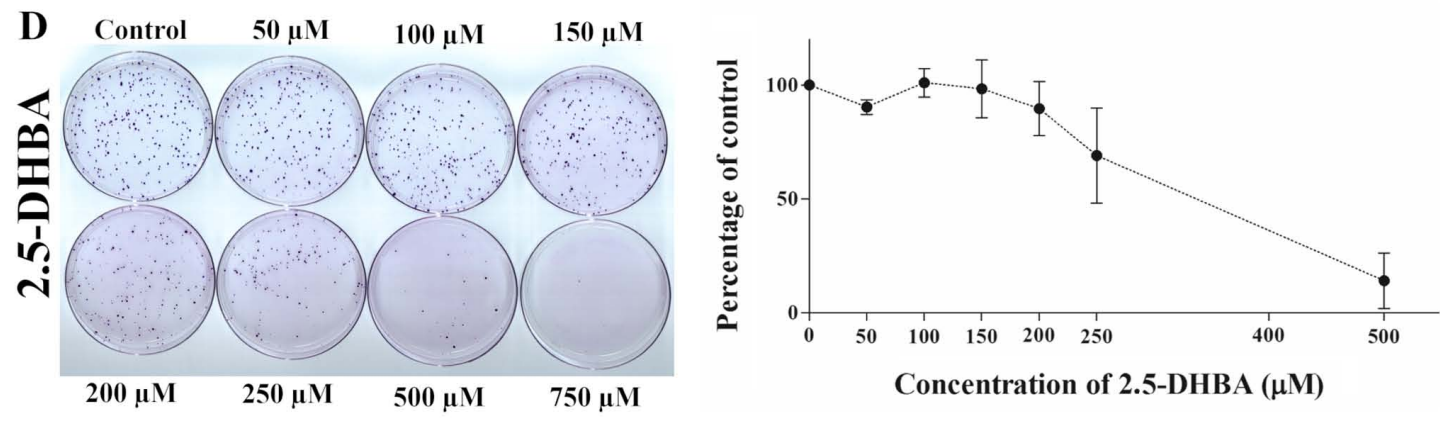

Figure 7. Effect of (A) aspirin, (B) salicylic acid, (C) 2,3-DHBA and (D) 2,5-DHBA on colony formation in HT-29 cells. Quantification of the data is shown beside the crystal violet stained image of the colonies. The graph is represented as mean \pm standard deviation. 2,3-DHBA, 2,3-dihydroxybenzoic acid; 2,5-DHBA, 2,5-dihydroxybenzoic acid.

HT-29 and MDA-MB-231 cells to aspirin or salicylic acid (up to $1 \mathrm{mM}$ ) failed to inhibit clonal formation, it is likely that the contributions of cellular CYP450s to the formation of 2,3-DHBA and 2,5-DHBA is negligible, although a small amount may still be produced through this route. We have not determined the effect of aspirin and salicylic acid on clonal formation at concentrations greater than $1 \mathrm{mM}$, therefore we are not sure if higher concentrations will have an effect on clonal formation. An alternative possibility and an attractive hypothesis is that the significant amount of aspirin/salicylic acid left unabsorbed (32-50\%) in the lumen of the intestine and colon maybe metabolized by the intestinal microflora to generate hydroxyl derivatives of salicylic acid, which may include both 2,3-DHBA and 2,5-DHBA. Bacteria are capable of metabolizing drugs through hydroxylations (55), and one report in 2016 showed that incubation of aspirin with human fecal suspensions containing microbiota resulted in the degradation of aspirin to salicylic acid and hydroxylated salicylic acids (30). The authors also showed that in rats orally administered with aspirin and ampicillin, the bioavailability of aspirin in the plasma was much higher compared to rats administered with aspirin alone, suggesting that microbiota contributes to the degradation of aspirin in the GI tract. An estimation of the salicylic acid present in the lumen of human gut has not been made, nor has the characterization of the hydroxyl derivatives of salicylic acid produced in the lumen been reported till date. 

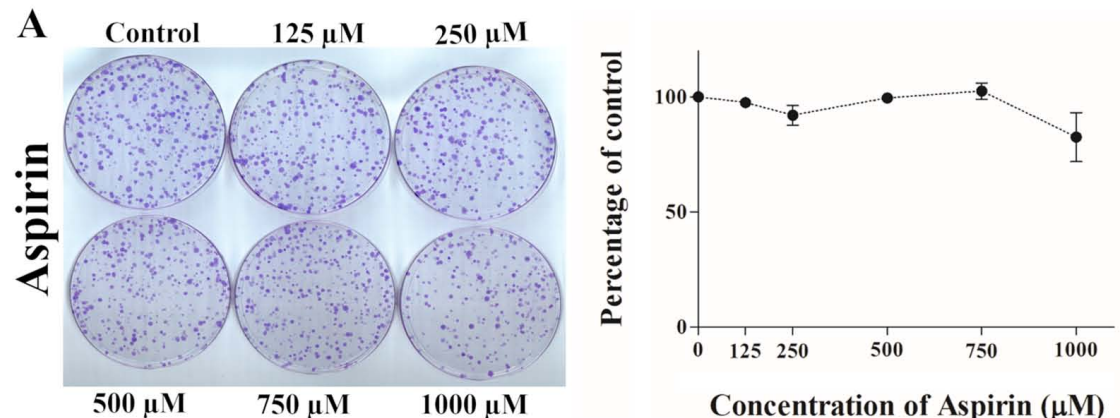

Concentration of Aspirin $(\mu \mathrm{M})$
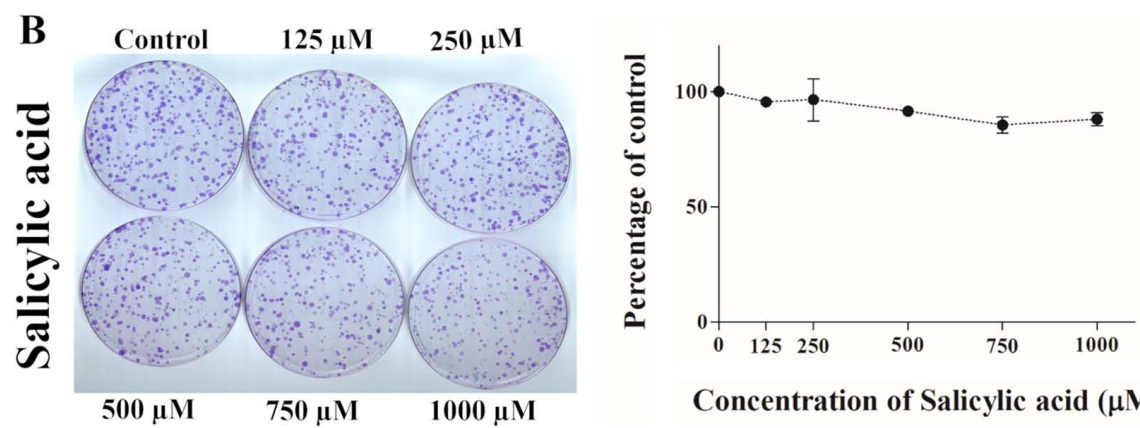

Concentration of Salicylic acid $(\mu \mathrm{M})$
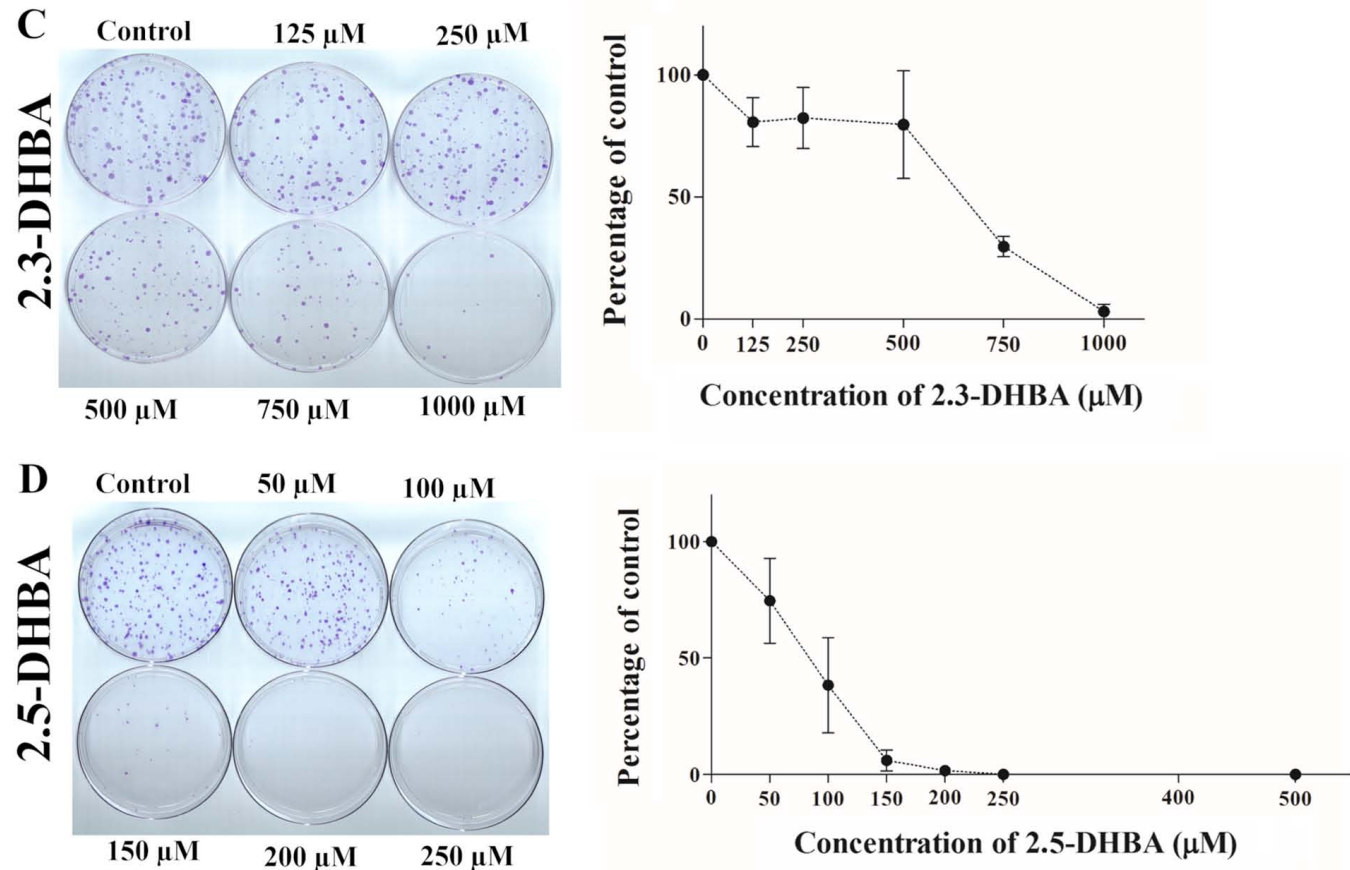

Figure 8. Effect of (A) aspirin, (B) salicylic acid, (C) 2,3-DHBA and (D) 2,5-DHBA on colony formation in MDA-MB-231 cells. Quantification of the data is shown beside the crystal violet stained image of the colonies. The graph is represented as mean \pm standard deviation. 2,3-DHBA, 2,3-dihydroxybenzoic acid; 2,5-DHBA, 2,5-dihydroxybenzoic acid.

The absence of experimental evidence on the potential formation of 2,3-DHBA and 2,5-DHBA, beyond what is reported in literature by Kim et al (30), is a limitation of this study. Further work is also required to determine how these metabolites are taken up by the normal, non-cancerous epithelial cells of the intestine and colon and their effect on colony formation, which is also a limitation of this study. Regarding the uptake mechanism, one possibility is that 2,3-DHBA and 2,5-DHBA may be taken up by the monocarboxylate transporter (MCT) SLC5A8 as it is implicated in the transport of other derivatives of salicylic acid (36). The differential sensitivity of HCT-116 and HT-29 vs. MDA-MB-231 could be attributed to the differential expression of this transporter due to mutational/ methylation-driven inactivation of the SLC5A8 gene as previously reported (56).

We observed that 2,5-DHBA was universally effective in inhibiting colony formation as compared to 2,3-DHBA. Significant inhibition of clonal formation was observed with 2,5-DHBA at $500 \mu \mathrm{M}$ in HCT-116 cells, at $250 \mu \mathrm{M}$ in HT-29 cells and at $100 \mu \mathrm{M}$ in MDA-MB-231 cells, whereas 2,3-DHBA failed to inhibit colony formation in HT-29 and HCT-116 cells (125-1,000 $\mu \mathrm{M})$. However, it inhibited the colony formation at $\sim 500 \mu \mathrm{M}$ in MDA-MB-231 cells. It appears that 2,3-DHBA and 2,5-DHBA show differential inhibitory effects 

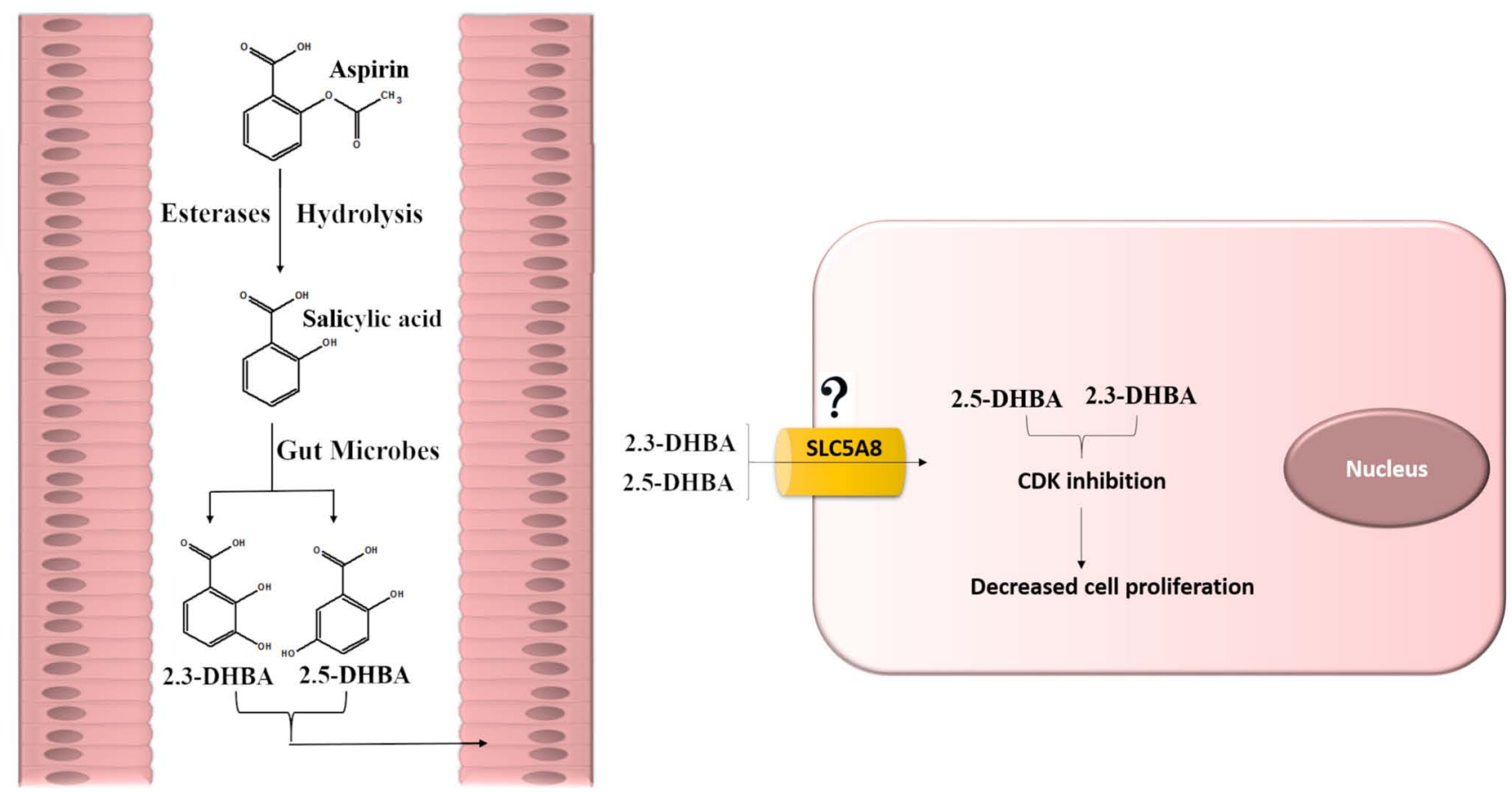

Figure 9. A model depicting how aspirin metabolites may exert its chemopreventive effects on colonic tissue to protect against CRC. It was hypothesized that aspirin and salicylic acid may impede events/pathways crucial to tumor formation through its metabolites 2,3-DHBA and 2,5-DHBA. It was suggested that 2,3-DHBA and 2,5-DHBA generated from salicylic acid by the action of gut microflora is taken up by the colonic epithelial cells. The uptake of these metabolites may occur through SLC5A8, a monocarboxylic acid transporter. Accumulation of these metabolites within the epithelial cells may result in CDK inhibition. This may cause reduced cell proliferation, allowing an opportunity for DNA repair and immune surveillance, thereby preventing tumorigenesis. Alternatively, it is also possible that 2,3-DHBA and 2,5-DHBA may have additional targets contributing to cancer prevention. 2,3-DHBA, 2,3-dihydroxybenzoic acid; 2,5-DHBA, 2,5-dihydroxybenzoic acid.

in different cancer cell lines and it is unclear whether this is due to the differences in uptake of these compounds by the cell lines tested. Two other salicylic acid derivatives namely 2,4-DHBA and 2,6-DHBA failed to inhibit colony formation in MDA-MB-231 cells (Fig. S1). This suggests that among the different salicylic acid derivatives tested, 2,5-DHBA is universally effective whereas 2,3-DHBA is more selective as an anti-proliferative agent. This observation is similar to our previous report in which we showed that another salicylic acid derivative and flavonoid metabolite 2,4,6-THBA is a potent inhibitor of colony formation in cells expressing functional SLC5A8 (36).

In contrast to the inhibitory effect of 2,3-DHBA and 2,5-DHBA in clonal formation (21 days), both compounds failed to show any appreciable inhibitory effect on cell number when cells were treated for 24-48 h (acute treatment) at various concentrations (125 to $1,000 \mu \mathrm{M}$; see Fig. S2). Similarly, in acute treatment experiments, both compounds failed to show an effect on cell cycle progression as measured by flow cytometry, and owing to the lack of an effect, we have not included this data. This discrepancy in the results between acute and chronic treatment may be related to the time required for uptake and accumulation of these compounds to exert an inhibitory effect. We suggest that acute exposure for 24-48 $\mathrm{h}$ may result in limited uptake of the drugs resulting in milder effects which are difficult to discern in flow cytometry analysis and cell counting, whereas chronic exposure for 21 days may result in significant accumulation of the drugs sufficient to cause inhibition of cell proliferation as measured by clonal formation assays. As we have not performed flow cytometry analysis on clonal cells following chronic exposure, it is not clear what stages of the cell cycle are affected by these compounds, and this is another limitation of the study.

Although the $\mathrm{IC}_{50}$ of the compounds tested in this study are in micromolar concentrations for both CDK inhibition and clonal formation, it could be argued that it is physiologically relevant in view of their abundance in the intestine due to the hydrolysis of aspirin to salicylic acid in the gut $(51,52)$. It is also important to note that 2,3-DHBA and 2,5-DHBA are abundantly available in fruits and vegetables (57) and one study demonstrated that the phenolic acid content generated from the diet in the gut can rise to micromolar concentrations (58). CDKs and other potential cellular targets probably have evolved to be less sensitive to these compounds to avoid complete inhibition of cell cycle at lower concentrations. The importance of 2,5-DHBA in cancer prevention was also demonstrated in a recent study which showed that it is effective in inhibiting colony formation and DNA synthesis in C6 glioma cells in vitro, and enhanced survival of Ehrlich breast ascites carcinoma bearing mice (59). In addition, 2,5-DHBA has been implicated in a previous report as a potential aspirin metabolite formed through the action of tyrosinase enzyme in melanoma cells. The study stated that p-quinone formation from 2,5-DHBA was responsible for aspirin's anti-melanoma effects through ROS formation (60). Thus, although both the studies implicate anti-cancer effects of 2,5-DHBA, the mechanisms described are starkly different; in melanocytes it occurs through depletion of GSH and generation of ROS leading to cell apoptosis (60), while in our study (in HT-29, HCT-116, and MDA-MB-231 cells) it likely involves inhibition of CDKs 
leading to suppression of cancer cell growth. This suggest that 2,5-DHBA may contribute to anti-cancer effects through distinct mechanisms in different cell types.

The demonstration of 2,3-DHBA and 2,5-DHBA to inhibit cancer cell growth is a significant observation in view of aspirin's reported ability to decrease CRC. An unanswered question is: What is/are the target(s) for 2,3-DHBA and 2,5-DHBA in cells? Our previously published data (31) and the present study show that 2,3-DHBA and 2,5-DHBA inhibited CDK1/CDK6 activity. However, at this stage it is not known if these two observations are related, or if the inhibition of proliferation by these compounds is due to an alternative mechanism not involving CDKs. In this context, a previous study reported that 2,5-DHBA can interfere with FGF function by disrupting the receptor-growth factor signaling complex in vitro and in cell culture studies (61). At this stage, we believe that 2,5-DHBA does not target COX-2 to mediate its chemo-preventive effect in the GI epithelial cells as HCT-116 cells are reported to lack COX-2 expression while HT-29 cells express inactive COX-2 (62). Since both these cell lines were inhibited by 2,5 -DHBA, it suggests that the aspirin metabolites can inhibit cancer cell proliferation through a COX-2 independent mechanism. Therefore, greater efforts need to be placed into these relatively unexplored areas to determine how 2,3-DHBA and 2,5-DHBA exert their chemopreventive actions. Whether microbiota generated salicylic acid metabolites becomes available for CDK inhibition following their uptake into the GI cells is an interesting area for future study. If proven, this will highlight the contribution of the gut microflora to aspirin's chemoprevention against CRC, through formation of 2,3-DHBA and 2,5-DHBA. A model depicting how 2,3-DHBA and 2,5-DHBA generated in the GI lumen through the microbial degradation of aspirin/salicylic acid, leading to inhibition of CDKs and cell proliferation is shown in Fig. 9. We suggest that the ability of aspirin to inhibit tumor formation in the intestinal/colonic mucosa may be a local effect via salicylic acid metabolites generated in the gut acting on epithelial cells, and may not require absorption into the blood.

Nearly 35 years have passed since the initial report of aspirin's ability to decrease incidences of CRC (63), however, debates still continue on its mode of action. Although the platelet hypothesis is widely discussed in literature, it has its own short-comings and appears to work indirectly through a set of sequential steps involving two COX isoforms (COX-1 and $\mathrm{COX}-2$ ) (9-14). COX-1 is the only form of $\mathrm{COX}$ in platelets and is constitutively expressed in all tissues, whereas COX-2 is inducible and expressed under inflammatory conditions. COX-2 levels are also elevated in many cancers $(48,64-67)$. The half-life of intact aspirin is about 15-20 min (68) in the systemic circulation and this period appears to be enough to cause inhibition of COX-1 in platelets (1). As chronic inflammation is linked to cancer, it is suggested that aspirin may mediate its effect through inhibition of these COX enzymes. However, aspirin is more effective in the inhibition COX-1 $\left(\mathrm{IC}_{50} 1.67 \mu \mathrm{M}\right)$ than COX-2 ( $\left.\mathrm{IC}_{50} 278 \mu \mathrm{M}\right)(69)$. Since low dose aspirin (75-160 mg) is as effective as higher doses (6), the possibility of aspirin directly targeting COX-2 as a potential mechanism to decrease cancer is thought to be unlikely because lower doses administered per day is insufficient to cause COX-2 inhibition. It is suggested that aspirin's effects may involve sequential inhibition of COX-1 and COX-2 $(9,10,12)$. This theory states that inhibition of COX-1 in platelets leads to prevention of platelet aggregation which subsequently prevents the release of lipid mediators (e.g., PGE-2; TXA2), cytokines and growth factors (e.g., PDGF) from the alpha-granules. These events could inhibit the induction of COX-2 in regions of GI mucosal lesions, preventing tumorigenesis.

If inhibition of COX-1 in platelets in the blood following its absorption is the primary mechanism as proposed in the platelet hypothesis (9-11), one would expect aspirin to decrease the incidences of cancer to the same extent in all tissues in the body, unless one assumes that GI mucosal tissues are more prone to lesions which leads to platelet aggregation, creating an environment suitable for eliciting an inflammatory response. It is intriguing that aspirin that is only present for less than $20 \mathrm{~min}$. in the circulation, while capable of preventing platelet activation and aggregation, could have such a profound effect against CRC development. While inhibition of COX-1 in platelets may play a role (e.g., in the inhibition of metastasis), it is likely that other pathways may play a more significant role in aspirin's cancer preventive actions.

Although the 'platelet hypothesis' is an attractive theory, we suggest that alternative mechanisms as proposed in this study involving locally generated salicylic acid metabolites by the gut microflora from aspirin as potential contributors to chemoprevention should be considered. As $\sim 50 \%$ of orally administered aspirin is left unabsorbed in the GI lumen $(51,52)$, one would expect the concentration of aspirin from an $81 \mathrm{mg}$ tablet to be in the range of 0.3 to $1.4 \mathrm{mM}$ in the gut assuming that the total GI fluid volume under fed and fasting conditions are $\sim 750$ and $\sim 160 \mathrm{ml}$ respectively (70). Presence of microflora in the GI lumen may thus be able to generate 2,3-DHBA and/or 2,5-DHBA from aspirin/salicylic acid, sufficient to cause inhibition of cell proliferation, allowing aspirin to act locally on colorectal tissues, thus adding merit to our hypothesis. In our opinion, locally generated metabolites will provide a more direct effect on colorectal tissues against CRC as compared to the indirect mechanism involving sequential steps proposed in platelet hypothesis through COX-1 and COX-2 inhibition. In vivo studies utilizing germ-free mice should shed light on the role of aspirin/salicylic metabolites and the microflora in aspirin's chemo-preventive properties.

\section{Acknowledgements}

The authors would like to thank Dr Hemachand Tummala (Department of Pharmaceutical Sciences, South Dakota State University) for the helpful discussions and Ms. Vijaya Gaddipati (volunteer researcher; Department of Pharmaceutical Sciences, South Dakota State University) for assisting in cell culture studies.

\section{Funding}

The present study was funded by The National Institutes of Health (grantno.5R03CA133061-02)and Research/Scholarship Support Fund 2018 from The Office of Research, South Dakota State University to GJB. 


\section{Availability of data and materials}

The datasets used and/or analyzed during the present study are available from the corresponding author on reasonable request.

\section{Authors' contributions}

GJB and RS conceptualized the study. CKV, RD and TL contributed to the experimental work. DRK and RS conducted the formal analysis (molecular docking). GJB and RS performed the experimental investigation and analysis. RS and GJB wrote the manuscript. All authors read and approved the final manuscript.

\section{Ethics approval and consent to participate}

Not applicable.

\section{Patient consent for publication}

Not applicable.

\section{Competing interests}

The authors declare that they have no competing interests.

\section{References}

1. Vane JR and Botting RM: The mechanism of action of aspirin Thromb Res 110: 255-258, 2003.

2. Vane JR: Inhibition of prostaglandin synthesis as a mechanism of action for aspirin-like drugs. Nat New Biol 231: 232-235, 1971

3. Roth GJ and Majerus PW: The mechanism of the effect of aspirin on human platelets. I. Acetylation of a particulate fraction protein. J Clin Invest 56: 624-632, 1975.

4. Hennekens $\mathrm{CH}$ : Update on aspirin in the treatment and prevention of cardiovascular disease. Am J Manag Care 8 (22 Suppl): S691-S700, 2002.

5. Rothwell PM, Price JF, Fowkes FG, Zanchetti A, Roncaglioni MC, Tognoni G, Lee R, Belch JF, Wilson M, Mehta Z and Meade TW: Short-term effects of daily aspirin on cancer incidence, mortality, and non-vascular death: Analysis of the time course of risks and benefits in 51 randomised controlled trials. Lancet 379: 1602-1612, 2012.

6. Rothwell PM, Wilson M, Elwin CE, Norrving B, Algra A, Warlow CP and Meade TW: Long-term effect of aspirin on colorectal cancer incidence and mortality: 20-year follow-up of five randomised trials. Lancet 376: 1741-1750, 2010.

7. Rothwell PM, Wilson M, Price JF, Belch JF, Meade TW and Mehta Z: Effect of daily aspirin on risk of cancer metastasis: A study of incident cancers during randomised controlled trials. Lancet 379: 1591-1601, 2012.

8. Bibbins-Domingo K; U.S. Preventive Services Task Force: Aspirin use for the primary prevention of cardiovascular disease and colorectal cancer: U.S. Preventive services task force recommendation statement. Ann Intern Med 164: 836-845, 2016.

9. Thun MJ, Jacobs EJ and Patrono C: The role of aspirin in cancer prevention. Nat Rev Clin Oncol 9: 259-267, 2012.

10. Patrono C: The Multifaceted clinical readouts of platelet inhibition by low-dose aspirin. J Am Coll Cardiol 66: 74-85, 2015.

11. Patrignani $P$ and Patrono $C$ : Aspirin, platelet inhibition and cancer prevention. Platelets 29: 779-785, 2018.

12. Patrignani $\mathrm{P}$ and Patrono C: Aspirin and cancer. J Am Coll Cardiol 68: 967-976, 2016.

13. Dovizio M, Alberti S, Guillem-Llobat P and Patrignani P: Role of platelets in inflammation and cancer: Novel therapeutic strategies. Basic Clin Pharmacol Toxicol 114: 118-127, 2014.

14. Chan AT, Arber N, Burn J, Chia WK, Elwood P, Hull MA, Logan RF, Rothwell PM, Schrör K and Baron JA: Aspirin in the chemoprevention of colorectal neoplasia: An overview. Cancer Prev Res (Phila) 5: 164-178, 2012.
15. Kopp E and Ghosh S: Inhibition of NF-kappa B by sodium salicylate and aspirin. Science 265: 956-959, 1994.

16. Dovizio M, Bruno A, Tacconelli S and Patrignani P: Mode of action of aspirin as a chemopreventive agent. Recent Results Cancer Res 191: 39-65, 2013.

17. Din FV, Valanciute A, Houde VP, Zibrova D, Green KA, Sakamoto K, Alessi DR and Dunlop MG: Aspirin inhibits mTOR signaling, activates AMP-activated protein kinase, and induces autophagy in colorectal cancer cells. Gastroenterology 142: 1504-1515.e3, 2012.

18. Hawley SA, Fullerton MD, Ross FA, Schertzer JD, Chevtzoff C, Walker KJ, Peggie MW, Zibrova D, Green KA, Mustard KJ, et al: The ancient drug salicylate directly activates AMP-activated protein kinase. Science 336: 918-922, 2012.

19. Gala MK and Chan AT: Molecular pathways: Aspirin and Wnt signaling-a molecularly targeted approach to cancer prevention and treatment. Clin Cancer Res 21: 1543-1548, 2015.

20. Ai G, Dachineni R, Muley P, Tummala H and Bhat GJ: Aspirin and salicylic acid decrease c-Myc expression in cancer cells: A potential role in chemoprevention. Tumour Biol 37: 1727-1738, 2016.

21. Goel A, Chang DK, Ricciardiello L, Gasche C and Boland CR: A novel mechanism for aspirin-mediated growth inhibition of human colon cancer cells. Clin Cancer Res 9: 383-390, 2003.

22. Pietrocola F, Castoldi F, Markaki M, Lachkar S, Chen G, Enot DP, Durand S, Bossut N, Tong M, Malik SA, et al: Aspirin recapitulates features of caloric restriction. Cell Rep 22: 2395-2407, 2018.

23. Ai G, Dachineni R, Kumar DR, Marimuthu S, Alfonso LF and Bhat GJ: Aspirin acetylates wild type and mutant p53 in colon cancer cells: Identification of aspirin acetylated sites on recombinant p53. Tumour Biol 37: 6007-6016, 2016.

24. Ai G, Dachineni R, Kumar DR, Alfonso LF, Marimuthu S and Bhat GJ: Aspirin inhibits glucose-6-phosphate dehydrogenase activity in HCT 116 cells through acetylation: Identification of aspirin-acetylated sites. Mol Med Rep 14: 1726-1732, 2016.

25. Rigas B and Tsioulias GJ: The evolving role of nonsteroidal anti-inflammatory drugs in colon cancer prevention: A cause for optimism. J Pharmacol Exp Ther 353: 2-8, 2015.

26. Bosetti C, Rosato V, Gallus S, Cuzick J and La Vecchia C: Aspirin and cancer risk: A quantitative review to 2011. Ann Oncol 23: 1403-1415, 2012.

27. Harris RE, Beebe-Donk J, Doss H and Burr Doss D: Aspirin, ibuprofen, and other non-steroidal anti-inflammatory drugs in cancer prevention: A critical review of non-selective COX-2 blockade (review). Oncol Rep 13: 559-583, 2005.

28. Cao Y, Nishihara R, Wu K, Wang M, Ogino S, Willett WC, Spiegelman D, Fuchs CS, Giovannucci EL and Chan AT: Population-wide impact of long-term use of aspirin and the risk for cancer. JAMA Oncol 2: 762-769, 2016.

29. Bojić M, Sedgeman CA, Nagy LD and Guengerich FP: Aromatic hydroxylation of salicylic acid and aspirin by human cytochromes P450. Eur J Pharm Sci 73: 49-56, 2015.

30. Kim IS, Yoo DH, Jung IH, Lim S, Jeong JJ, Kim KA, Bae ON, Yoo HH and Kim DH: Reduced metabolic activity of gut microbiota by antibiotics can potentiate the antithrombotic effect of aspirin. Biochem Pharmacol 122: 72-79, 2016.

31. Dachineni R, Kumar DR, Callegari E, Dachineni R, Kumar DR, Callegari E, Kesharwani SS, Sankaranarayanan R, Seefeldt T, Tummala $\mathrm{H}$ and Bhat GJ: Salicylic acid metabolites and derivatives inhibit CDK activity: Novel insights into aspirin's chemopreventive effects against colorectal cancer. Int J Oncol 51: 1661-1673, 2017.

32. DK2 kinase assay, https://www.signalchem.com/shared product_sheets/N211-4.pdf.

33. CDK1 Kinase assay, https://www.signalchem.com/shared_ product_sheets/F625-2.pdf.

34. CDK4 Kinase assay, https://www.signalchem.com/shared product_sheets/R219-1.pdf.

35. CDK6 Kinase assay, https://www.signalchem.com/shared product_sheets/D062-1.pdf.

36. Sankaranarayanan R, Valiveti CK, Kumar DR, Van Slambrouck $S$, Kesharwani SS, Seefeldt T, Scaria J, Tummala H and Bhat GJ: The flavonoid metabolite 2,4,6-trihydroxybenzoic acid is a CDK inhibitor and an anti-proliferative agent: A potential role in cancer prevention. Cancers (Basel) 11: pii: E427, 2019.

37. Dachineni R, Ai G, Kumar DR, Sadhu SS, Tummala H and Bhat GJ: Cyclin A2 and CDK2 as novel targets of aspirin and salicylic acid: A potential role in cancer prevention. Mol Cancer Res 14: 241-252, 2016. 
38. Van Der Spoel D, Lindahl E, Hess B, Groenhof G, Mark AE and Berendsen HJ: GROMACS: Fast, flexible, and free. J Comput Chem 26: 1701-1718, 2005.

39. Wu SY, McNae I, Kontopidis G, McClue SJ, McInnes C, Stewart KJ, Wang S, Zheleva DI, Marriage H, Lane DP, et al Discovery of a novel family of CDK inhibitors with the program LIDAEUS: Structural basis for ligand-induced disordering of the activation loop. Structure 11: 399-410, 2003.

40. Din FV, Dunlop MG and Stark LA: Evidence for colorectal cancer cell specificity of aspirin effects on NF kappa B signalling and apoptosis. Br J Cancer 91: 381-388, 2004.

41. Qiao L, Hanif R, Sphicas E, Shiff SJ and Rigas B: Effect of aspirin on induction of apoptosis in HT-29 human colon adenocarcinoma cells. Biochem Pharmacol 55: 53-64, 1998.

42. Dibra HK, Brown JE, Hooley P and Nicholl ID: Aspirin and alterations in DNA repair proteins in the SW480 colorectal cancer cell line. Oncol Rep 24: 37-46, 2010.

43. Chen J and Stark LA: Aspirin prevention of colorectal cancer: Focus on NF- $x \mathrm{~B}$ signalling and the nucleolus. Biomedicines 5: pii: E43, 2017.

44. Mitrugno A, Sylman JL, Ngo AT, Pang J, Sears RC, Williams CD and McCarty OJ: Aspirin therapy reduces the ability of platelets to promote colon and pancreatic cancer cell proliferation: Implications for the oncoprotein c-MYC. Am J Physiol Cell Physiol 312: C176-C189, 2017.

45. Ma J, Cai Z, Wei H, Liu X, Zhao Q and Zhang T: The anti-tumor effect of aspirin: What we know and what we expect. Biomed Pharmacother 95: 656-661, 2017.

46. Bruno A, Dovizio M, Tacconelli S, Contursi A, Ballerini P and Patrignani P: Antithrombotic agents and cancer. Cancers (Basel) 10: pii: E253, 2018

47. Cox D, Maree AO, Dooley M, Conroy R, Byrne MF and Fitzgerald DJ: Effect of enteric coating on antiplatelet activity of low-dose aspirin in healthy volunteers. Stroke 37: 2153-2158, 2006.

48. Dovizio M, Maier TJ, Alberti S, Di Francesco L, Marcantoni E, Münch G, John CM, Suess B, Sgambato A, Steinhilber D and Patrignani P: Pharmacological inhibition of platelet-tumor cell cross-talk prevents platelet-induced overexpression of cyclooxygenase-2 in HT29 human colon carcinoma cells. Mol Pharmacol 84: 25-40, 2013.

49. Lichtenberger LM, Fang D, Bick RJ, Poindexter BJ, Phan T, Bergeron AL, Pradhan S, Dial EJ and Vijayan KV: Unlocking aspirin's chemopreventive activity: Role of irreversibly inhibiting platelet cyclooxygenase-1. Cancer Prev Res (Phila) 10: 142-152, 2017.

50. Inoue $\mathrm{M}$, Morikawa M, Tsuboi M, Ito $\mathrm{Y}$ and Sugiura $\mathrm{M}$ : Comparative study of human intestinal and hepatic esterases as related to enzymatic properties and hydrolizing activity for ester-type drugs. Jpn J Pharmacol 30: 529-535, 1980.

51. Pedersen AK and FitzGerald GA: Dose-related kinetics of aspirin. Presystemic acetylation of platelet cyclooxygenase. N Engl J Med 311: 1206-1211, 1984.

52. Rowland M, Riegelman S, Harris PA and Sholkoff SD: Absorption kinetics of aspirin in man following oral administration of an aqueous solution. J Pharm Sci 61: 379-385, 1972

53. Haastrup PF, Gronlykke T and Jarbol DE: Enteric coating can lead to reduced antiplatelet effect of low-dose acetylsalicylic acid. Basic Clin Pharmacol Toxicol 116: 212-215, 2015.

54. Gervot L, Carriere V and Costet P: CYP3A5 is the major cytochrome P450 3A expressed in human colon and colonic cell lines. Environ Toxicol Pharmacol 2: 381-388, 1996.
55. Swanson HI: Drug metabolism by the host and gut microbiota: A partnership or rivalry? Drug Metab Dispos 43: 1499-1504, 2015.

56. Ganapathy V, Thangaraju M, Gopal E, Martin PM, Itagaki S, Miyauchi S and Prasad PD: Sodium-coupled monocarboxylate transporters in normal tissues and in cancer. AAPS J 10: 193-199, 2008.

57. Juurlink BH, Azouz HJ, Aldalati AM, AlTinawi BM and Ganguly P: Hydroxybenzoic acid isomers and the cardiovascular system. Nutr J 13: 63, 2014.

58. Jenner AM, Rafter J and Halliwell B: Human fecal water content of phenolics: The extent of colonic exposure to aromatic compounds. Free Radic Biol Med 38: 763-772, 2005.

59. Altinoz MA, Elmaci I, Cengiz S, Emekli-Alturfan E and Ozpinar A: From epidemiology to treatment: Aspirin's prevention of brain and breast-cancer and cardioprotection may associate with its metabolite gentisic acid. Chem Biol Interact 291: 29-39, 2018.

60. Vad NM, Yount G and Moridani MY: Biochemical mechanism of acetylsalicylic acid (Aspirin) selective toxicity toward melanoma cell lines. Melanoma Res 18: 386-399, 2008.

61. Fernández IS, Cuevas P, Angulo J, López-Navajas P, Canales-Mayordomo A, González-Corrochano R, Lozano RM, Valverde S, Jiménez-Barbero J, Romero A and Giménez-Gallego G: Gentisic acid, a compound associated with plant defense and a metabolite of aspirin, heads a new class of in vivo fibroblast growth factor inhibitors. J Biol Chem 285: 11714-11729, 2010.

62. Hsi LC, Baek SJ and Eling TE: Lack of cyclooxygenase-2 activity in HT-29 human colorectal carcinoma cells. Exp Cell Res 256 $563-570,2000$.

63. Kune GA, Kune S and Watson LF: Colorectal cancer risk, chronic illnesses, operations, and medications: Case control results from the melbourne colorectal cancer study. Cancer Res 48: 4399-4404, 1988.

64. Eberhart CE, Coffey RJ, Radhika A, Giardiello FM, Ferrenbach S and DuBois RN: Up-regulation of cyclooxygenase 2 gene expression in human colorectal adenomas and adenocarcinomas. Gastroenterology 107: 1183-1188, 1994.

65. Sano H, Kawahito Y, Wilder RL, Hashiramoto A, Mukai S, Asai K, Kimura S, Kato H, Kondo $\mathrm{M}$ and Hla T: Expression of cyclooxygenase-1 and -2 in human colorectal cancer. Cancer Res 55: 3785-3789, 1995.

66. Gupta RA and Dubois RN: Colorectal cancer prevention and treatment by inhibition of cyclooxygenase-2. Nat Rev Cancer 1: $11-21,2001$

67. Kargman SL, O'Neill GP, Vickers PJ, Evans JF, Mancini JA and Jothy S: Expression of prostaglandin $\mathrm{G} / \mathrm{H}$ synthase -1 and -2 protein in human colon cancer. Cancer Res 55: 2556-2559, 1995.

68. Costello PB and Green FA: Aspirin survival in human blood modulated by the concentration of erythrocytes. Arthritis Rheum 25: 550-555, 1982

69. Vane JR, Bakhle YS and Botting RM: Cyclooxygenases 1 and 2. Annu Rev Pharmacol Toxicol 38: 97-120, 1998.

70. Schiller C, Fröhlich CP, Giessmann T, Siegmund W, Mönnikes H, Hosten $\mathrm{N}$ and Weitschies W: Intestinal fluid volumes and transit of dosage forms as assessed by magnetic resonance imaging. Aliment Pharmacol Ther 22: 971-979, 2005.

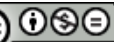

This work is licensed under a Creative Commons Attribution-NonCommercial-NoDerivatives 4.0 International (CC BY-NC-ND 4.0) License. 